\title{
Evaluating the Thermal Vinylcyclopropane Rearrangement (VCPR) as a Practical Method for the Synthesis of Difluorinated Cyclopentenes: Experimental and Computational Studies of Rearrangement Stereospecificity
}

\author{
David Orr, ${ }^{a}$ Prof. Dr. Jonathan M. Percy, ${ }^{\star a}$ Dr. Tell Tuttle, ${ }^{a}$ Dr. Alan R. Kennedy, ${ }^{a}$ and Dr. Zoë A. \\ Harrison $^{a}$
}

\begin{abstract}
Vinyl cyclopropane rearrangement (VCPR) has been utilised to synthesise a difluorinated cyclopentene stereospecifically and under mild thermal conditions. Difluorocyclopropanation chemistry afforded ethyl 3-(1'(2'2'-difluoro-3'-phenyl)cyclopropyl) propenoate as all four stereoisomers (18a, 18b, 22a, 22b) (all racemic). Trans- $E$ isomer (18a), prepared in $70 \%$ yield over three steps, underwent near quantitative VCPR to difluorocyclopentene $\mathbf{2 3}$ (99\%). Rearrangements were followed by ${ }^{19} \mathrm{~F}$ NMR $\left(100-180{ }^{\circ} \mathrm{C}\right)$. While cis/trans cyclopropane stereoisomerisation was facile, favouring trans-isomers by a modest margin, no $E / Z$ alkene isomerisation was observed even at higher temperatures. Neither cis nor trans Z-alkenoates underwent VCPR, even up to much higher temperatures $\left(180{ }^{\circ} \mathrm{C}\right)$. Cis-cyclopropanes underwent $[3,3]-$ rearrangement to afford benzocycloheptadiene species. The reaction stereospecificity was explored using electronic structure calculations and UB3LYP/6-31G* methodology allowed the energy barriers for cyclopropane stereoisomerisation, diastereoisomeric VCPR and [3,3]-rearrangement to be ranked in agreement with experiment.
\end{abstract}

\section{Introduction}

The rearrangement of vinylcyclopropanes to cyclopentenes (the vinylcyclopropane rearrangement, VCPR) has developed rapidly from its initial discovery by Neureiter over 70 years ago, ${ }^{1}$ becoming an important transformation in the synthesis of a variety of complex natural products. ${ }^{2}$ The synthetic scope of the reaction has expanded significantly; ${ }^{3,4}$ while the prototypical reaction of $\mathbf{1}$ to 2 required high temperatures for the

[a] David Orr, Prof. Dr. Jonathan M. Percy, ${ }^{*}$ Dr. Tell Tuttle, Dr. Alan R. Kennedy

WestCHEM Department of Pure and Applied Chemistry,

University of Strathclyde,

Thomas Graham Building, 295 Cathedral Street,

Glasgow G1 1XL (UK). Fax: (+44) 0141-548-4822.

E-mail: david.orr@strath.ac.uk, jonathan.percy@strath.ac.uk.

[b] Dr. Zoë A. Harrison

Refractory Respiratory Inflammation DPU,

GlaxoSmithKline Medicines Research Centre,

Gunnels Wood Road, Stevenage,

SG1 2NY (UK). Fax: (+44) 01438768302.

Email: zoe.x.harrison@gsk.com

Supporting information for this article is available on the WWW under http://dx.doi.org/10.1002/chem.2014xxxx rearrangement of the simple parent hydrocarbon ${ }^{5,6}$ (Scheme 1), substrate modifications ${ }^{7}$ and the deployment of transition metal catalysts ${ }^{8,9,10}$ have even allowed the rearrangement to be carried out at room temperature in some cases.

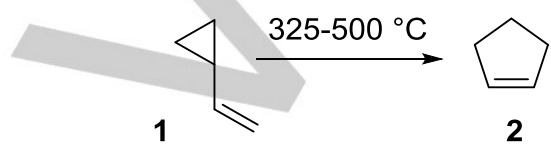

Scheme 1. Prototypical vinylcyclopropane rearrangement (VCPR).

Rearrangements which can be carried out at lower temperature are desirable because they minimise the risk of competing and unwanted stereoisomerisation ${ }^{11,12}$ and homodienyl [1,5]-hydrogen shifts. ${ }^{13}$

The activation energy for the prototypical VCPR was independently reported by Wellington ${ }^{14}(50 \pm 0.3 \mathrm{kcal} / \mathrm{mole})$ and Baldwin $^{15}(51.7 \pm 0.5 \mathrm{kcal} / \mathrm{mole})$ to be approximately 13 $\mathrm{kcal} / \mathrm{mole}$ less than the energy required to break a cyclopropane C-C bond. ${ }^{16}$ The similarity of that quantity to the resonance stabilisation energy of the allyl radical (calculated as $12.4 \pm 0.6$ $\mathrm{kcal} / \mathrm{mole}^{17}$ ) supports the idea that the rearrangement proceeds via diradical intermediates strongly. Difluorinated $3^{18,19}$ and perfluorinated $4 \mathrm{a}^{20}$ precursors (Figure 1 ) have lower activation energies by up to 10.3 and $17.1 \mathrm{kcal} / \mathrm{mole}$ respectively. More recently, Smart and co-workers reported that pentafluorinated 4b underwent facile rearrangement, with the lowest reported activation energy of $28.4 \mathrm{kcal} / \mathrm{mole}(23.3 \mathrm{kcal} / \mathrm{mole}$ less than the prototypical VCPR). ${ }^{21}$ This was attributed to the higher strain energy of fluorinated cyclopropanes. O'Neal and Benson ${ }^{22}$ proposed that the strain energy increases by approximately 5 $\mathrm{kcal} / \mathrm{mole}$ per fluorine atom; this idea was later supported by experimental ${ }^{19}$ and computational work. ${ }^{23}$ Extensive studies by Dolbier and co-workers ${ }^{24,25}$ showed that gem-difluorinated cyclopropanes undergo regiospecific ring opening via cleavage of the weaker distal carbon-carbon bond.
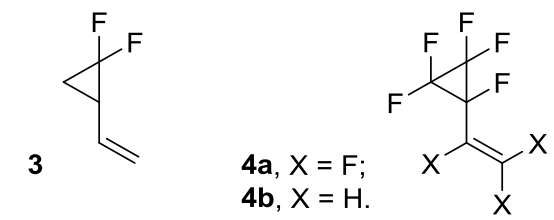

Figure 1. Fluorinated VCPR precursors from the literature.

Despite these seminal and fundamental studies of reactivity, the VCPR has not been deployed as a method for the synthesis of difluorinated cyclopentenes. Because of Dolbier's recent significant progress in difluorocyclopropanation methodology, ${ }^{26}$ 
we sought to develop a building block approach ${ }^{27}$ to difluorinated cyclopentenes based on the VCPR, which would exploit fluorine atom effects to decrease the reaction temperatures of the simple thermal rearrangements.

The proposed strategy was based on the synthesis of difluorinated analogue 8 of a Dictyopterene pheromone found in brown algae, reported by Boland and $\operatorname{Erbes}^{28}$ (Scheme 2).

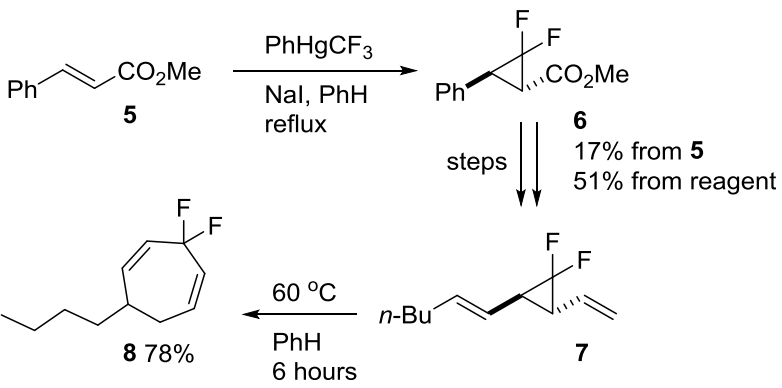

Scheme 2. Boland and Erbes' synthesis of Dictyopterene analogue 8.

The conversion of alkenoate 5 to cyclopropane 6 required the use of Seyferth's reagent $\left(\mathrm{PhHgCF}_{3}\right)$, the most reactive difluorocarbene transfer reagent available. The reaction was sacrificial in $\mathbf{5}$, and the yield of cyclopropanation was only moderate $(51 \%$ based on the reagent). Seyferth's reagent is highly toxic and is not readily available, limiting its utility considerably. With the alkenyl groups in place, the diyl rearrangement of $\mathbf{7}$ to $\mathbf{8}$ was efficient and facile.

Difluorocyclopropanation of E-cinnamyl acetate $\mathbf{9}$, then ester hydrolysis to 11 , followed by tandem oxidation/olefination would secure VCPR precursor 12 via a simple and direct sequence (Scheme 3), setting the stage for rearrangement to 13. One prerequisite for a successful route would be a highly efficient difluorocyclopropanation of $\mathbf{9}$.

A very wide range of difluorocyclopropanation reagents is now available (Figure 2). ${ }^{29-31}$ Inexpensive sodium chlorodifluoroacetate has been used to transform relatively electron-deficient substrates like 9 but significant excesses of the reagent are usually required. ${ }^{32-34}$

$$
\begin{array}{ll}
\mathrm{XF}_{2} \mathrm{CSiMe}_{3} & \mathrm{O}_{\mathrm{O}} \mathrm{O} \\
14 \mathrm{a}, \mathrm{X}=\mathrm{Cl} ; & 15 \mathrm{a}, \mathrm{X}=\mathrm{SiMe}_{3} ; \\
14 \mathbf{b}, \mathrm{X}=\mathrm{Br} & 15 \mathbf{b}, \mathrm{X}=\mathrm{Me} .
\end{array}
$$

Figure 2. Selected reagents used for difluorocyclopropanation.

Seyferth's reagent ${ }^{35,36}$ was unacceptable, so we sought more recent methods. $\mathrm{Hu}$ et al. ${ }^{37}$ used (chlorodifluoromethyl)trimethylsilane $14 a$ (prepared from bromochloro-difluoromethane ${ }^{38}$ ) as a difluorocarbene precursor, securing difluorocyclopropanes from a range of alkenes and alkynes. More recently the same group reported that a more general reagent, (bromodifluoromethyl)trimethylsilane 14b, could not only effect cyclopropanation but also difluoromethylate oxygen, sulfur, nitrogen and phosphorus nucleophiles. ${ }^{39}$

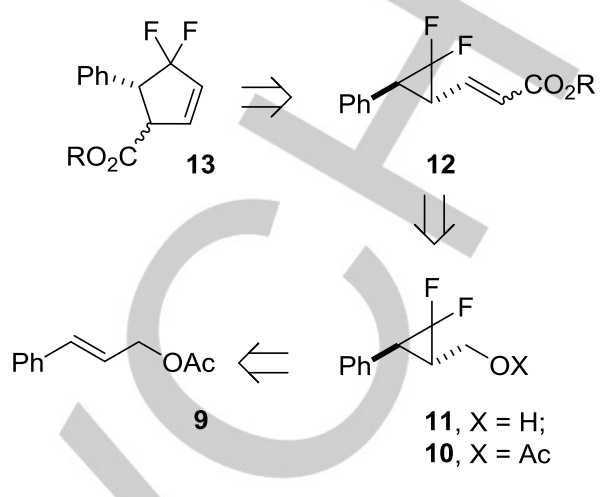

Scheme 3. Proposed route to difluorinated cyclopentene 13.

While the reagent was effective in many cases, the yield of cyclopropane obtained from benzyl acrylate was only moderate (43\%). The current benchmark reagent, trimethylsilyl fluorosulfonyldifluoroacetate (TFDA) 15a was reported by Dolbier and co-workers in 2000. ${ }^{40}$ Fluoride-catalysed decomposition of $\mathbf{1 5 a}$ in the presence of alkenes results in efficient cyclopropanation; for example, the reaction with benzyl acrylate afforded the cyclopropane in $73 \%$ yield. More recently, the Gainesville group reported that the more robust methyl 2,2difluoro-2-(fluorosulfonyl)acetate (MDFA) 15b would effect many of the TFDA reactions successfully. ${ }^{26}$ These reagents looked like extremely promising starting points for our study.

\section{Results and Discussion}

Following disappointing results with a range of carbene precursors (see the Supporting Information for details), carbene formation and trapping was attempted with 9 and MFDA 15b under the conditions described by Dolbier. We failed to achieve full conversion of alkene $\mathbf{9}$ and isolated a previously unobserved side product (Table 1, Entry 1). The presence of iodide in the reaction mixture could result in $\left(S_{N} 2^{\prime}\right)$ nucleophilic ring opening with strain relief to afford iodide 16; this side product could be isolated successfully from the crude reaction mixture using column chromatography, but the yellow/brown oil decomposed after storage in the refrigerator (see the Supporting Information for the ${ }^{1} \mathrm{H}$ and ${ }^{19} \mathrm{~F}$ NMR spectra which support the assignment). A 0.25 -fold increase in reagent excess over alkene 9 increased the conversion to $95 \%$ after 17 hours (Entry 2). The Dolbier group experienced similar problems during their optimisation, reporting that reducing the reaction concentration led to poorer yields. 


\begin{tabular}{|c|c|c|c|c|c|c|c|c|}
\hline & & $\mathrm{Ph}^{\sim}$ & 1,4 & 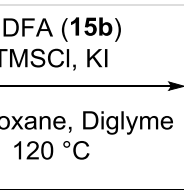 & & 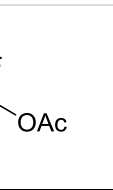 & 16 & \\
\hline Entry & $15 \mathrm{~b}$ (eq.) & TMSCI (eq.) & Dioxane (eq & Diglyme (eq.) & KI (eq.) & Time (h) & Conversion $(9: 10)^{[\mathrm{a}]}$ & Yield $(\%)^{[b]}$ \\
\hline 1 & 2 & 2 & 1.7 & 0.1 & 2.25 & 48 & $4: 80^{[c]}$ & 32 \\
\hline 2 & 2.46 & 2.46 & 1.87 & 0.11 & 2.77 & 17 & 1:19 & 43 \\
\hline 3 & 2.46 & 2.46 & 0 & $1.2^{[\mathrm{d}]}$ & 2.77 & 24 & $0: 1$ & 94 \\
\hline 4 & 2.46 & 2.46 & 0 & 1.2 & 2.7 & 4 & $0: 1$ & 85 \\
\hline
\end{tabular}

[a] determined by crude ${ }^{1} \mathrm{H}$ NMR. [b] Isolated yield. [c] Crude reaction mixture contained $16 \%$ of 16 ( ${ }^{1} \mathrm{H}$ NMR). [d] Reaction mixture went to dryness after 5 hours and an extra 1.2 eq. of was added.

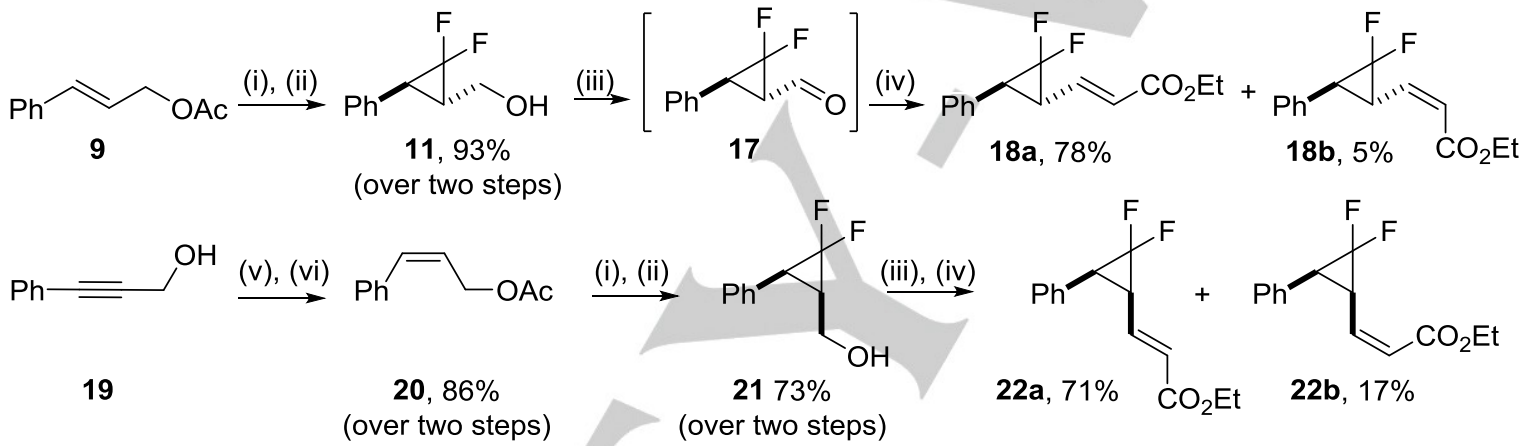

Scheme 4. Synthesis of VCPR precursors 18 and 22

Conditions: (i) MDFA (2.46 eq.), $\mathrm{TMSCl}$ (2.46 eq.), $\mathrm{KI}$ (2.77 eq.), diglyme (1.2 eq.), $120^{\circ} \mathrm{C}, 24 \mathrm{~h}$ (ii) $\mathrm{K}_{2} \mathrm{CO}_{3}$ ( 1 eq.), $\mathrm{MeOH} / \mathrm{H}_{2} \mathrm{O}, 60{ }^{\circ} \mathrm{C}, 2 \mathrm{~h}$ (iii) TEMPO (2,2,6,6tetramethylpiperidine 1-oxyl, 0.1 eq.), BAIB ( $\mathrm{Phl}(\mathrm{OAc})_{2}, 1.15$ eq.), $\mathrm{DCM}$, r.t., $6 \mathrm{~h}$ (iv) $\mathrm{Ph}_{3} \mathrm{P}=\mathrm{CHCO}_{2} \mathrm{Et}\left(1.3\right.$ eq.) $2-14 \mathrm{~h}(\mathrm{v}) \mathrm{H}_{2}$ (1 eq., atm), Lindlar cat. (5 mol\% $\mathrm{Pd}$ ), $\mathrm{EtOH}$, r.t., $10 \mathrm{~h}$ (vi) $\mathrm{Ac}_{2} \mathrm{O}$ (1.05 eq.) DMAP (10 mol\%), DCM/pyridine, r.t., $22 \mathrm{~h}$.

The reaction in diglyme alone afforded 10 in high yield $(94 \%$; Entry 3) if an additional portion of diglyme was added when the reaction mixture started to solidify. When the reaction was stopped after only 4 hours, full conversion was achieved and the high yield of 10 was maintained (85\%; Entry 4).

Ester 10 was saponified to afford alcohol 11 in high yield (Scheme 4). Gram quantities of material could be brought through ( 8 mmole scale from 9 ), giving access to synthetically useful quantities of alcohol $\mathbf{1 1}$ over two steps. Vatéle's one-pot oxidation/olefination conditions ${ }^{41}$ were implemented next because they avoided isolation of potentially fragile aldehyde 17. Oxidation of 11 by a TEMPO-BAIB combination, gave full conversion to aldehyde 17 after 6 hours (the reaction was followed by ${ }^{19} \mathrm{~F} \quad \mathrm{NMR}$ ). Addition of (carbethoxymethylene)triphenylphosphorane afforded a separable mixture of $\mathbf{1 8 a}$ and $\mathbf{1 8 b}$ ( $95: 5$ by ${ }^{1} \mathrm{HNMR}$ ).

The cis-precursors were prepared from 19, via Lindlar reduction and acetylation ( $86 \%$ over 2 steps); elaboration as before afforded 22a (71\%) and 22b (17\%) after the oxidation/olefination step. Cyclopropane and alkene relative configuration was confirmed by NOESY and ${ }^{1} \mathrm{H}$ NMR respectively for all four products (see the Supporting Information).

We found that $18 a$ rearranged smoothly to difluorocyclopentene 23 even at $90{ }^{\circ} \mathrm{C}$ (Table 2, Entry 1). Cyclopropane stereoisomerisation was also observed (by ${ }^{19} \mathrm{~F}$ NMR after 6 hours); the cis diastereoisomer 22a was formed from pure trans $18 \mathbf{a}$, but thermolysis of the $\mathbf{1 8 a / 2 2 a}$ mixture resulted in the formation of unique difluorocyclopentene product 23. The product connectivity was established by $2 D$ NMR (HSQC/HMBC) and the trans-configuration was assigned from ${ }^{1} \mathrm{H} /{ }^{1} \mathrm{H}$ and ${ }^{1} \mathrm{H} /{ }^{19} \mathrm{~F}$ NMR coupling constant analysis (see the Supporting Information for details). The assignment was confirmed when $\mathbf{2 3}$ was oxidised to crystalline epoxide $\mathbf{2 4}$ (Scheme 5) using methyl(trifluoromethyl)dioxirane prepared according to a modification of a published procedure ${ }^{42}$ described by the Baran group. ${ }^{43}$ The original trans-relationship and the unexpected facial selectivity (vide infra) were shown by the elucidation of the molecular structure in the crystal (see the Supporting Information for more details and a discussion). 
Table 2. Selected optimisation results for thermal VCPR of $\mathbf{1 8 a}$ and $\mathbf{2 2 a}$

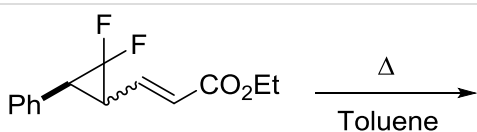

$18 \mathbf{a}$ or $22 a$
Toluene

23<smiles>CCOC(=O)C1C=CC(F)=Cc2ccccc21</smiles>

$25 a$

\begin{tabular}{|c|c|c|c|c|c|c|c|c|}
\hline \multirow{2}{*}{ Entry } & \multirow{2}{*}{ VCP } & \multirow{2}{*}{$\operatorname{Temp}\left({ }^{\circ} \mathrm{C}\right)$} & \multirow{2}{*}{ Time (h) } & \multicolumn{3}{|c|}{ Conversion $^{[\mathrm{a}]}$} & & \multirow{2}{*}{ Yield $(\%)^{[\mathrm{b}]}$} \\
\hline & & & & $18 a$ & $22 a$ & 23 & $25 a$ & \\
\hline \multirow[b]{2}{*}{1} & & & 6 & 1 & 0.19 & 0.63 & 0 & \\
\hline & $18 a$ & 90 & 26 & 1 & 0 & & 0 & - \\
\hline $2^{[c]}$ & $18 a$ & 90 & 6 & 1 & 0.14 & 0.11 & 0 & - \\
\hline $3^{[\mathrm{d}]}$ & $18 a$ & 90 & 22 & 1 & 0 & 33 & 17 & $-[e]$ \\
\hline 4 & $18 a$ & 100 & 17 & 0 & 0 & 1 & 0 & 99 \\
\hline 5 & $22 a$ & 100 & 24 & 0 & 0 & 1 & 0 & 93 \\
\hline
\end{tabular}

[a] Ratio determined by ${ }^{19} \mathrm{~F}$ NMR. [b] Isolated yield. [c] Microwave irradiation. [d] Neat reaction mixture. [e] $\mathbf{2 5 a}$ isolated in $19 \%$ yield.<smiles>CCOC(=O)[C@H]1C=CC(F)(F)[C@@H]1c1ccccc1</smiles><smiles>[Ca]</smiles>

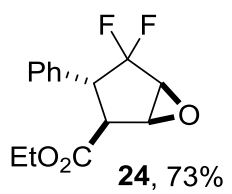

Scheme 5. Dioxirane oxidation of VCPR product 23.

Conditions:(i) Methyl(trifluoromethyl)dioxirane (ca. 3.4 eq.) in trifluoroacetone, $-78^{\circ} \mathrm{C}, 1 \mathrm{~h}$ then r.t., $1 \mathrm{~h}$.

Microwave irradiation resulted in slower rearrangement (Entry 2), but neat 18a was consumed more rapidly under conventional heating. Under these conditions, side product $25 \mathrm{a}$ was also formed. [3,3]-Rearrangement ${ }^{44}$ of cis-cyclopropane 22a followed by dehydrofluorination/rearomatisation of the initial educt (vide infra) results in the formation of $25 \mathrm{a}$; the connectivity was established by $2 \mathrm{D}$ NMR methods (see the Supporting Information for details). The side reaction could be avoided when the reaction was run in toluene at $100{ }^{\circ} \mathrm{C}$ (Entry 4). Upon full conversion (determined by ${ }^{19} \mathrm{~F}$ NMR) under these conditions, the reaction solvent was removed to afford a very high yield of 23 from 18a (99\%); 22a also rearranged exclusively to 23 in excellent $(93 \%)$ yield under the same conditions (Entry 5) (see the Supporting Information for examples of crude VCPR spectra) The relatively high reactivity of our precursor system is consistent with the presence of the $\mathrm{CF}_{2}$ centre and the development of benzylic radical character; Ingold ${ }^{45}$ and Newcomb ${ }^{46,47}$ showed that cyclopropyl radical ring opening was accelerated strongly when the product radical was benzylic. Roth and co-workers showed that the VCPR of $\mathbf{3}$ only occurred above $200{ }^{\circ} \mathrm{C}^{19}$ so the phenyl group is providing strong activation.

This VCPR represents a direct and effective way of making difluorinated cyclopentenes. Whereas radical cyclisation methods (based on tin hydride chemistry) were deployed by

several groups to access difluorinated cyclopentanes, ${ }^{48-50}$ DAST or DeoxoFluor ketone transformations have secured difluorinated cyclopentanones, ${ }^{51}$ and Nazarov cyclisations ${ }^{52}$ difluorinated cyclopentenones, difluorinated cyclopentenes are relatively unusual motifs in the synthetic literature. ${ }^{53}$ Qing and co-workers ${ }^{54}$ used RCM to form the key cyclopentene ring of carbanucleosides in which $\mathrm{CF}_{2}$ replaces a furanyl ring oxygen, and Itoh has also used an RCM approach in which difluorocyclopropane ring-opening fulfils a pivotal role. ${ }^{55}$ Our VCPR-based approach combines ease of preparation (4 highyielding steps from commercially available reagents) with an attractive range of functional groups for further transformation. Previously we have used difluorinated cycloalkenes as precursors to difluorinated carbasugar analogues, ${ }^{56-58}$ and exploited the Sharpless oxidation of phenyl groups in syntheses of difluorinated aldoses. ${ }^{59}$

To investigate the role of cyclopropane stereoisomerisation more fully, the reactions of both $\mathbf{1 8 a}$ and $22 \mathrm{a}$ were followed by ${ }^{19} \mathrm{~F}$ NMR at $373 \mathrm{~K}$ in $d_{8}$-toluene (see the Supporting Information for experimental detail). As shown in Table 2, 18a transformed smoothly to 23 , but 22 a also formed, reaching a maximum at about $13 \%$ of the reaction mixture after 10 minutes, and then decaying slowly, showing that cyclopropane stereoisomerisation (Figure 3a) competes effectively with VCPR. This was observed more clearly when the reaction was started from 22a; within 15 minutes, most of the cis-cyclopropane had isomerised to the trans-diastereoisomer $\mathbf{1 8 a}$, which then reacted through to $\mathbf{2 3}$ (Figure 3b).

The concentration/time profiles could be simulated successfully as far as experimental endpoints at 10 hours using numerical integration software (see the Supporting Information for details) based on the simple model of Scheme 6 . 

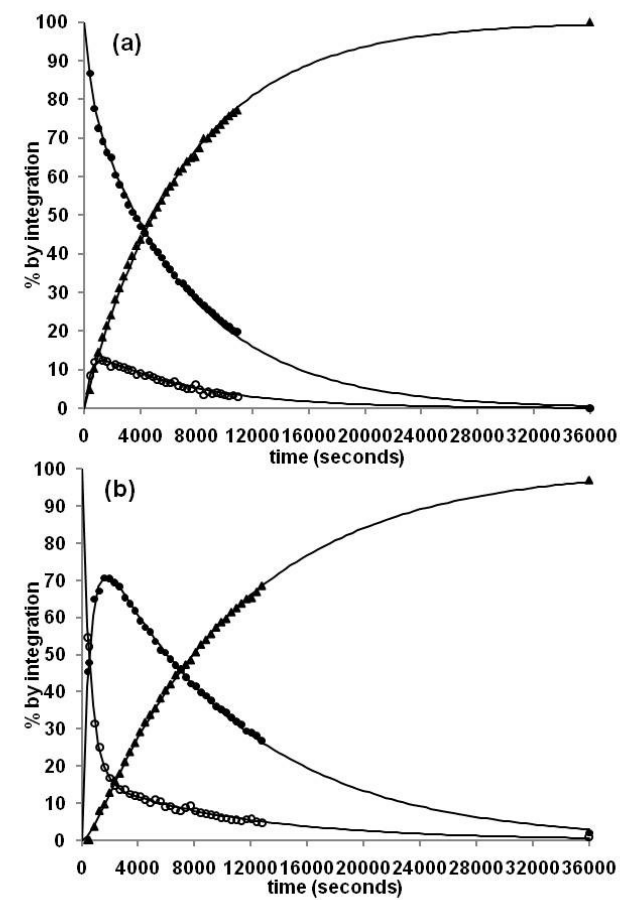

Figure 3. Experimental (points) and simulated (lines) concentration/time profile for thermolysis $(373 \mathrm{~K}$ ) of a) $\mathbf{1 8 a}$; b) $\mathbf{2 2 a}$; $18 \mathbf{a}=\bullet, \mathbf{2 2 a}=\circ, 23=\Delta$ )

Deconvolution of the rate constants (Table 3 ) highlighted the modest equilibrium constant between trans and cis cyclopropanes (5.4 starting from trans, 5.6 starting from cis, in favour of the trans-diastereoisomer) and the facile stereoisomerisation (the rate constant is an order of magnitude higher than that for VCPR).

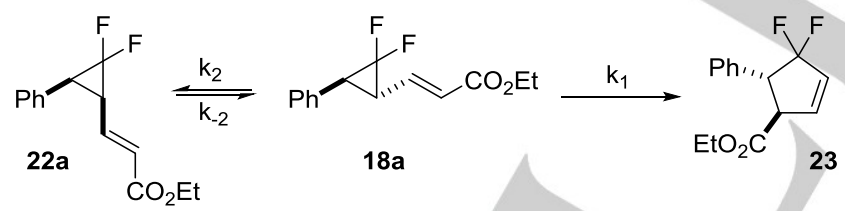

Scheme 6. Kinetic model used in the simulation of parallel VCPR and stereoisomerisation pathways.

Table 3. Rate constants extracted from reaction simulation.

\begin{tabular}{ccccc}
\hline Substrate & $\mathbf{1 0}^{\mathbf{4}} \mathbf{k}_{\mathbf{1}}\left(\mathbf{s}^{-1}\right)$ & $\mathbf{1 0}^{\mathbf{4}} \mathbf{k}_{\mathbf{2}}\left(\mathbf{s}^{-1}\right)$ & $\mathbf{1 0}^{\mathbf{4}} \mathbf{k}_{\mathbf{- 2}}\left(\mathbf{s}^{-1}\right)$ & $\mathbf{k}_{-2} / \mathbf{k}_{\mathbf{2}}$ \\
\hline $\mathbf{1 8 a}$ & 1.6 & 3.5 & 19.1 & 5.4 \\
$\mathbf{2 2 a}$ & 1.1 & 2.6 & 14.7 & 5.6 \\
\hline
\end{tabular}

An approximate Arrhenius determination of activation parameters was carried out by taking the best first-order fit of the data from VCPR of 18a from NMR experiments (363-393 K, $\mathrm{d}_{8-}$ $\mathrm{PhMe}$ ) (see the Supporting Information for experimental detail); a value for $E_{a}$ of $29.2 \pm 0.6 \mathrm{kcal} \mathrm{mol}^{-1}$, not unlike that obtained by
Smart and co-workers $\left(28.4 \mathrm{kcal} \mathrm{mol}^{-1}\right.$ at $\left.373 \mathrm{~K}\right)$ for thermolysis of $\mathbf{4 b}$.

We failed entirely to detect VCPR from either $Z$ species (18b or 22b) (Figure 4); only stereoisomerisation was detectable when either $\mathbf{1 8 b}$ or $\mathbf{2 2 b}$ was heated in $\mathrm{d}_{8}$-PhMe at $373 \mathrm{~K}$. Equilibrium constants of 3.7 (from 18b) and 3.6 (from 22b) favouring $18 \mathrm{~b}$ were extracted from the simulation data and confirmed by integration of the ${ }^{19} \mathrm{~F}$ NMR spectra (see the Supporting Information).

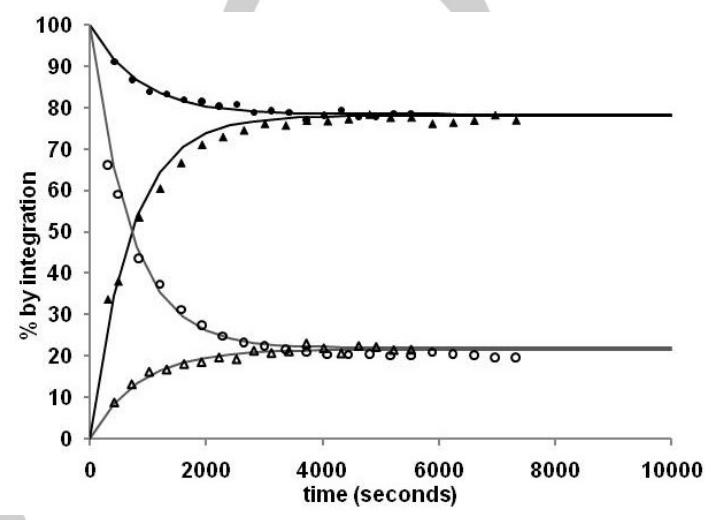

Figure 4. Experimental (points) and simulated (lines) concentration/time profile for thermolysis of $\mathbf{1 8 b}$ and $22 \mathrm{~b}$ (starting from: - 18b from 18b $\Delta$ 18b from $22 b \circ 22 b$ from $22 b \Delta 22 b$ from $18 b\left(d_{8}-P h M e, 373 \mathrm{~K}\right)$ ).

At higher temperature $\left(180{ }^{\circ} \mathrm{C}\right), \mathbf{1 8 b}$ underwent [3,3]rearrangement to $25 \mathrm{a}$ and $\mathbf{2 5 b}\left(10: 1\right.$ by ${ }^{19} \mathrm{~F}$ NMR integration) (Scheme 7).

$$
\underbrace{}_{18 \mathrm{~b}} \frac{180^{\circ} \mathrm{C}}{\overline{\mathrm{Ph}_{2} \mathrm{O}}}
$$<smiles>CCOC(C)(F)C1=CCC(F)=Cc2ccccc21</smiles><smiles>C=COC(=CC1C(F)C1c1ccccc1)COCC</smiles>
22b<smiles>CCOC(=O)C1=CC=C(F)Cc2ccccc21</smiles>

Scheme 7. [3,3]-Rearrangement of Z-alkenoate precursors $\mathbf{1 8 b}$ and $\mathbf{2 2 b}$.

Stronger heating of $\mathbf{2 2} \mathbf{b}$ also returned a very similar mixture of $25 \mathrm{a}$ and $\mathbf{2 5 b}$ (9:1 by ${ }^{19} \mathrm{~F}$ NMR integration). De-aromatised intermediate $\mathbf{2 6}$ was never observed; elimination of HF driven by re-aromatisation would be anticipated strongly. Heating isolated 25a to $180^{\circ} \mathrm{C}\left(\mathrm{Ph}_{2} \mathrm{O}, 17.5\right.$ hours $)$ returned more fully conjugated 25b, presumably via an $[1,5]-\mathrm{H}$ shift; $25 \mathrm{c}$ (the product of $[1,3]-\mathrm{H}$ shift from 25a) was not detected.

The inertness of the Z-alkenoate precursors towards VCPR surprised us, but we failed to find examples of Z-alkenyl groups participating, apart from the deuterated species of Baldwin and co-workers. ${ }^{60,61}$ Sustmann $^{62}$ and co-workers prepared precursors with Z-alkenyl groups but did not report 
their behaviour under rearrangement conditions. Smart et al. ${ }^{21}$ heated a 5:1 mixture of $\mathbf{2 7 a}$ and $\mathbf{2 7 b}$, to form a 19:1 mixture of pentafluorocyclopentene $\mathbf{2 8}$ and unreacted Z-isomer 27b (Scheme 8). To our knowledge, Smart's result provides the only example of a Z-alkenyl motif taking part in VCPR; $\Delta \mathrm{G}^{\ddagger}(373 \mathrm{~K})$ for the VCPR of $27 \mathrm{~b}$ was measured at $31.1 \mathrm{kcal}$ mol-1, only ca. $3 \mathrm{kcal} \mathrm{mol}-1$ higher than that for $27 \mathrm{a}(28.5 \mathrm{kcal} \mathrm{mol}-1)$.<smiles>[X]C([X])=CC1(F)C(F)(F)C1(F)F</smiles>

27a, $X=\mathrm{H}, \mathrm{Y}=\mathrm{CH}_{3}$;

27b, $\mathrm{X}=\mathrm{CH}_{3}, \mathrm{Y}=\mathrm{H}$

Scheme 8. Convergence of diastereoisomeric alkene precursors through VCPR

The $E / Z$ reactivity difference is more dramatic in our system. This and other aspects of the reaction stereospecificity were now examined using electronic structure calculations.

Davidson and Gajewski, ${ }^{63}$ and Houk and co-workers, ${ }^{64,65}$ have used computational methods to study the vinylcyclopropane rearrangement. A detailed dynamics treatment has also been reported. ${ }^{66}$ The parent system 1 undergoes VCPR and stereoisomerisation competitively but the major reaction channel involves VCPR via the WoodwardHoffmann "allowed" suprafacial inversion (si) transition state TS1 leading to cyclopentene $\mathbf{2}$ (Scheme 9)<smiles>C=CC(C)CC(C)CCCC</smiles>

TS1

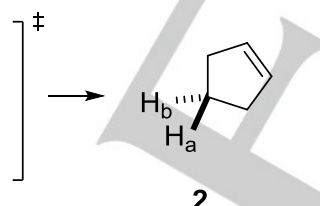

2
Scheme 9. VCPR si-Transition State TS1, showing the exchange of the $\mathrm{H}_{\mathrm{a}}$ and $\mathrm{H}_{\mathrm{b}}$ ligands through inversion at the migratory carbon centre.

In their seminal study, ${ }^{65}$ Houk and co-workers reported that unrestricted B3LYP ${ }^{67,68}$ (UB3LYP/6-31G*) predicted experimental VCPR activation energies well. However, more recent work ${ }^{62}$ has proposed a combination of Truhlar's M05-2X hybrid functional $\left.\right|^{69-71}$ and the $6-311+G^{* *}$ basis as a benchmarking method.

We chose to explore the effectiveness of a small matrix of methods for the prediction of VCPR barriers. We selected VCP/VCPR systems $1,3,4 b$ and $29 a$ (a conformationally simpler analogue of 18a) (Figure 5), and used B3LYP, M05-2X, M06-2X $X^{72}$ and B97-D ${ }^{73,74}$ functionals (all in unrestricted mode) with $6-31 G^{*}, 6-31+G^{*}$ and $6-311+G^{* *}$ basis sets to calculate barrier energies $\left(\Delta G^{\ddagger}\right)$. Geometry optimisations were performed in Gaussian'09, ${ }^{75}$ Spartan'08 ${ }^{76}$ or Spartan' $10 ;{ }^{77}$ the optimised geometries were characterised as minima or transition structures by performing harmonic frequency calculations.

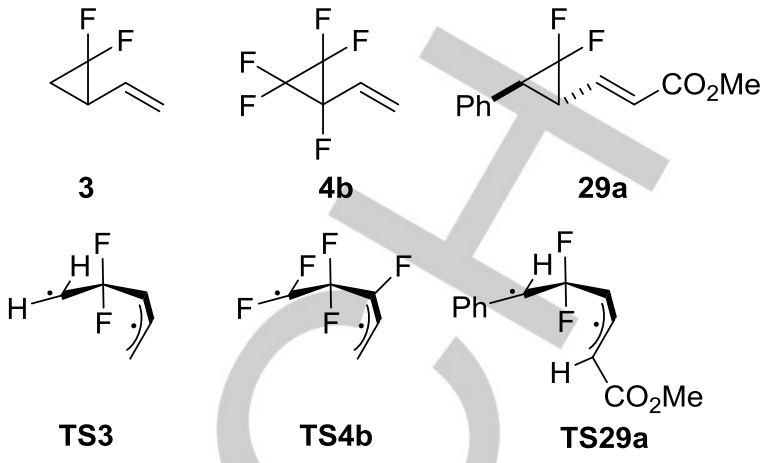

Figure 5. VCPR precursors and their corresponding transition states.

As the focus of our work is primarily synthetic, we wished to establish an effective method of lowest cost, so that we could use it for the design of new reaction systems which would undergo relatively facile rearrangement. In each case, the strans $Z$ or s-trans $E$ cyclopropane geometry and the transition structure on the suprafacial inversion (si) pathway were optimised with full frequency calculation. Because the dipoles of all the precursors and transition structures were small and similar (2.25-3.00 Debyes), and the toluene solvent used for the experimental work has a low dielectric constant $(\varepsilon=2.38)$, we have not applied solvation methods.

We used Houk's Cartesian coordinates ${ }^{65}$ for TS1 as a starting point for structure building and transition state searching; in the case of TS29a, a range of diastereoisomeric and conformationally isomeric species was explored (vide infra). Table 4 and Figure 6 compare the computational results to values of $\Delta G^{\ddagger}(298 \mathrm{~K})$ calculated from experimental Arrhenius parameters $\left(E_{a}, A\right)$ from the literature and from this work.

There were significant differences between the levels of performance of the functionals. UB3LYP underestimated the experimental barriers for all systems, with the discrepancy increasing with basis set size. UB97-D performed best with Smart's highly-fluorinated system but under-estimated barriers for the other systems with all basis sets. The imaginary frequencies calculated for TS4b and TS29a with UB97-D were much lower than with the other functionals, and the values of the spin operator $\left\langle S^{2}\right\rangle$ were 0 for $\mathbf{4 b}$ and $0.251-0.311$ for TS29a whereas consistently higher values were obtained with the other methods for all systems (see the Supporting Information for details).

The closest agreement with experimental values was obtained with UM05-2X/6-31+G* and UM05-2X/6-311+G** methods with $\Delta \Delta \mathrm{G}^{\ddagger}$ within $1 \mathrm{kcal} \mathrm{mol}^{-1}$ (overestimate) for 1, 3 and 29a, and within $2 \mathrm{kcal} \mathrm{mol}^{-1}$ (underestimate) for $4 \mathrm{~b}$. We also calculated the barriers to VCPR for diastereoisomeric 27a and 27b using the M05-2X/6-31+G* method, obtaining values of $\Delta G^{\ddagger}$ (at $298 \mathrm{~K}$ ) of 26.2 and $29.9 \mathrm{kcal} \mathrm{mol}^{-1}$ respectively, compared to the (approximate) experimental values (at $298 \mathrm{~K}$ ) of 27.8 and $29.9 \mathrm{kcal} \mathrm{mol}^{-1}$ respectively. 
Table 4. Barriers $\left(\Delta \mathrm{G}^{\ddagger}\right.$, gas phase, $\left.298 \mathrm{~K}, \mathrm{kcal} \mathrm{mol}^{-1}\right)$ for VCPR from electronic structure calculations (ESC) and recalculated ${ }^{78}$ from Arrhenius data. ${ }^{15,18,21}$

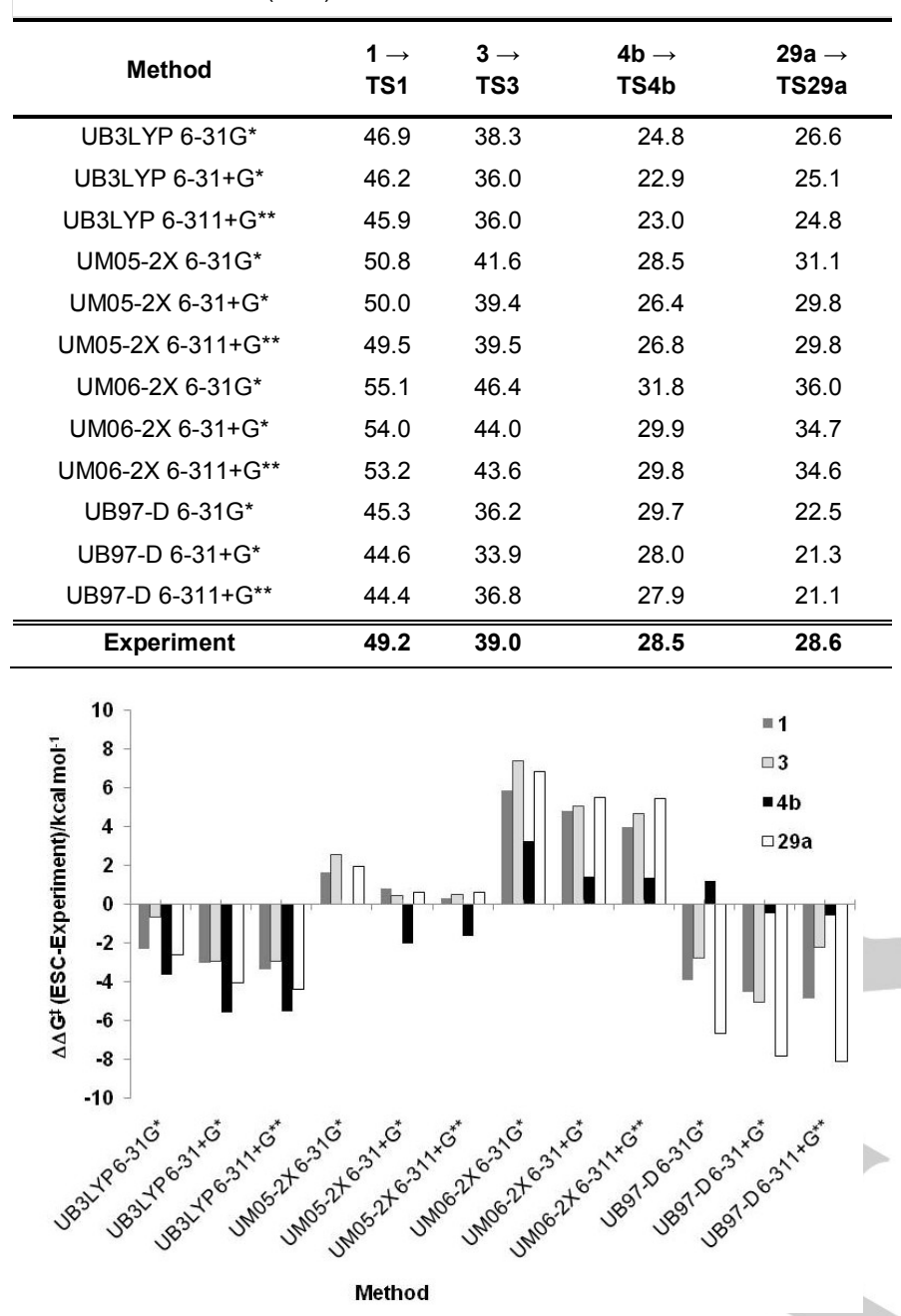

Figure 6. Differences between experimental $\Delta \mathrm{G}^{\ddagger}(298 \mathrm{~K}$, re-calculated from activation parameters) and $\Delta \mathrm{G}^{\ddagger}$ from electronic structure calculations (298 K), plotted as $\Delta \Delta \mathrm{G}^{\ddagger}\left(\Delta \mathrm{G}^{\ddagger}(\mathrm{ESC})-\Delta \mathrm{G}^{\ddagger}\right.$ (experimental), kcal $\left.\mathrm{mol}^{-1}\right)$. Expected error associated with data is $\pm 0.5 \mathrm{kcal} \mathrm{mol}^{-1}$.

The UM06-2X functional ${ }^{70}$ over-estimated the rearrangement barrier for 1,3 and 29 a by $4 \mathrm{kcal} \mathrm{mol}^{-1}$ or more, performing better for more highly-fluorinated $\mathbf{4 b}$. Smart's highly fluorinated $\mathbf{4 b}$ involves a different type of radical terminus from the other three systems; in $\mathbf{4 b}$, the inverting radical centre is difluorinated and pyramidal, whereas it is a trigonal centre (methylene, - $\mathrm{CH}_{2}$ in TS1 TS3) or a trigonal (benzylic methine, $\mathrm{CHPh}$ in TS29a) in the other systems. While there is no a priori reason why the level of theory used should deal with the highlyfluorinated system less well, there is a step change in structure between Smart's system and the other members of the test set.

While the UM05-2X/6-31+G* method gave the closest agreement between prediction and experimental values for this small test set, the consistency of performance of the UB3LYP/6$31 \mathrm{G}^{*}$ method suggested that it would be worthwhile to assess its ability to rationalise and predict the reaction stereospecificity.
Both methods were applied and the different free energies obtained are identified by a suffix in $\mathrm{G}_{\cup \mathrm{UM} 05-2 x}$ or $\mathrm{G}_{\text {Uвзьүр. }}$.

The important competing pathways are the cis/trans cyclopropane stereoisomerisation and the $[3,3]$-rearrangement of the cis-cyclopropane. We therefore set out to establish a minimal pathway for the former, because the full PES accessible from VCP 1 and mapped by Houk and co-workers was quite complex. ${ }^{65}$ IRCs were computed by Houk and co-workers from s-trans vinylcyclopropane for the facile stereomutation; Houk identified intermediate $\mathbf{3 0}$ and transition state $\mathbf{3 1}$, connected by rotation around a C-C $\sigma$-bond which cost ca. $15 \mathrm{kcal} \mathrm{mol}^{-1}$ from single point calculations) as accessible from 1 (Scheme 10).

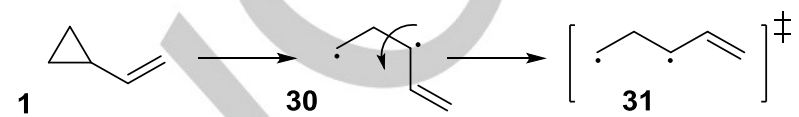

Scheme 10. Diradical species implicated in cyclopropane stereoisomerisation

We checked that an IRC lead to intermediates of this type by stretching the ring bond distal to the $\mathrm{CF}_{2}$ centre (using AM1 and the energy profile algorithm in Spartan'10). We then built a minimal set of triplet diradicals corresponding to the full VCPR systems.

Stretching the distal ring bond in the s-trans conformer of TS29a led to transoid triplet diradical 32a (Scheme 11); the locations of the $\mathrm{C}-4$ and $\mathrm{C}-6 \mathrm{C}-\mathrm{H}$ bonds echo their relative orientations in the VCP.

Conversion to cisoid triplet $\mathbf{3 2} \mathbf{b}$ could be achieved either by rotation around C-4/C-5 (dihedral $\varphi_{1}$ ) or C-5/C-6 (dihedral $\varphi_{2}$ ) bonds; carbons C-1, C-2, C-3 and C-4 stay mutually coplanar to preserve radical stabilisation via conjugation (which explains why alkenoate $E / Z$ stereoisomerisation was never observed). We found triplets $\mathbf{3 2 a}$ and $\mathbf{3 2} \mathbf{b}$ as minima, and connecting transition state 33 related by rotation around $\varphi_{2}$ (Figure 7). The Z-cyclopropane $\mathbf{3 4 a}$ and $\mathbf{3 4 b}$ could be interconverted by rotation around $\varphi_{2}$ via triplets $35 \mathbf{a}$ and $\mathbf{3 5 b}$, passing through transition state $\mathbf{3 6}$ (see the Supporting Information for details) at similar cost.

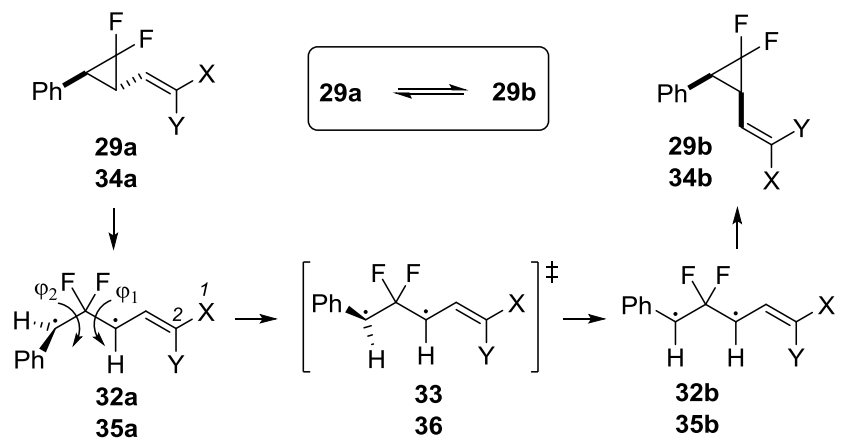

E-series 29a, 29b, 32a, 33, 32b; $X=\mathrm{CO}_{2} \mathrm{Me}, \mathrm{Y}=\mathrm{H}$; Z-series 34a, 34b, 35a, 36, 35b; $X=\mathrm{H}, \mathrm{Y}=\mathrm{CO}_{2} \mathrm{Me}$.

Scheme 11. Cyclopropane trans/cis stereoisomerisation via triplets. 
The interconversion was predicted to be more facile than VCPR by both methods (Table 5), consistent with the experimental findings, with the UM05-2X/6-31+G* method predicting a significantly higher barrier. (a)

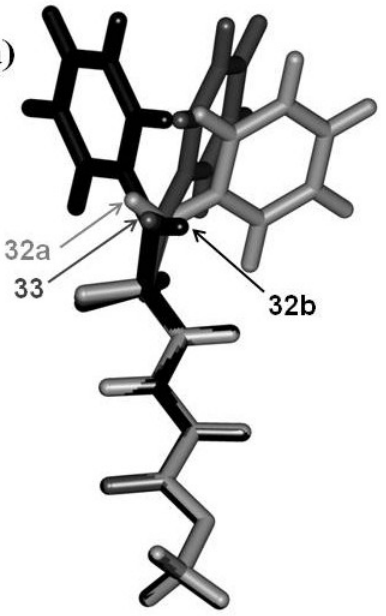

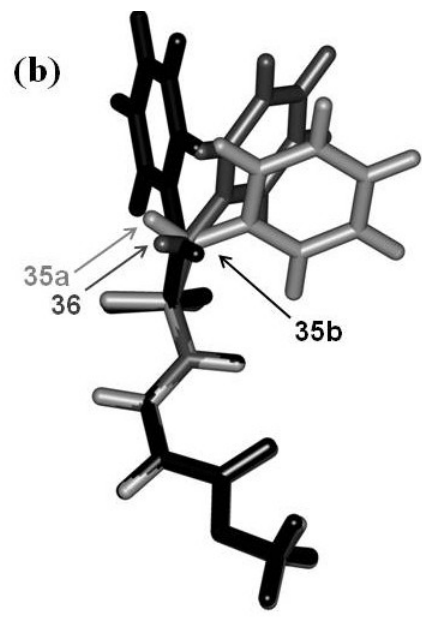

Figure 7. Triplet diradical structures which interconnect cis- and transcyclopropane structures for (a) $E$-alkenoate and (b) Z-alkenoate series.

The VCPR transition state develops from precursors in the gauche conformation; isotopic labelling has been used extensively in the literature to show that while the si pathway is the major one, it competes with others ( $a r$, ai and sr) to varying degrees depending on the number and site of isotopic labels. ${ }^{65}$ The introduction of much bigger groups could lead to one pathway being favoured more decisively; this was our expectation given the formation of a single trans-cyclopentene product.

The most logical progression of $29 \mathrm{a}$ would be through TS29a or TS29b (Scheme 12) which differ only in the ester conformation; inversion in the migrating benzylic centre means that by the time the transition state is reached, the phenyl group has swung into the correct orientation for the formation of the trans-cyclopentene product 37. TS29a $\left(\Delta \mathrm{G}^{\ddagger} \mathrm{uM} 05-2 \mathrm{X} 29.8 \mathrm{kcal}^{\mathrm{mol}}\right.$ 1 from 29a in the the $s$-trans conformation, referring to the orientation of cyclopropane and alkene) has the alkenoate in the $s$-cis, syn conformation, which is the favoured orientation for simpler systems like methyl acrylate ${ }^{79}$ TS29b has the ester $s$ trans syn at a cost of an additional $1 \mathrm{kcal} \mathrm{mol}^{-1}$ at the barrier $\left(\Delta \mathrm{G}^{\ddagger} \text { UM05-2X } 30.8 \mathrm{kcal} \mathrm{mol}^{-1}\right)^{80}$
Because the reactions appeared so stereospecific from the NMR experiments, we built and investigated a further six $s$ transition states; the variables were the alkene configuration ( $E$ or Z-) and the orientations of the $\mathrm{Ph}$ and $-\mathrm{CO}_{2} \mathrm{Me}$ groups.
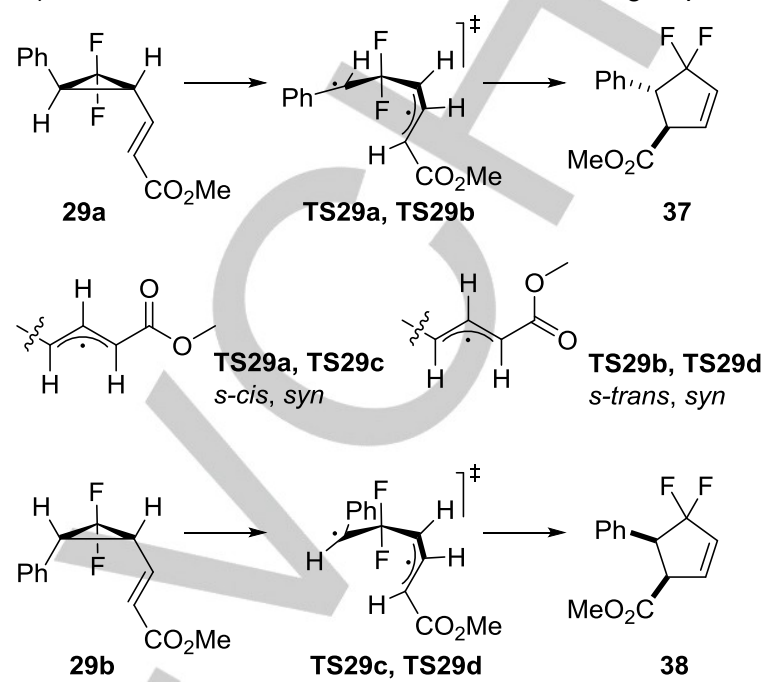

Scheme 12. Diastereoisomeric VCPR transition states.

The formation of cis-cyclopentene product $\mathbf{3 8}$ from these competitive transition states would be anticipated strongly, contrary to the experimental findings. Simulation of the reaction profile (see the Supporting Information) predicts that ciscyclopentene would make up to $20 \%$ of the product mixture when the rates of VCPR are the same for both cyclopropane diastereoisomers. An alternative explanation for the completely stereoselective VCPR would involve product epimerisation; there is a modest calculated driving force $\left(\Delta \Delta \mathrm{G}_{\mathrm{UM05}-2 \mathrm{X}}\right)$ for the cis/trans isomerisation of $\mathbf{3 8}$ to $\mathbf{3 7}$ of only $1.4 \mathrm{kcal} \mathrm{mol}^{-1}$ (or K = 6.3 at $373 \mathrm{~K}$ ) which is inadequate to explain the outcome. In contrast, the UB3LYP method predicted a kinetically transselective VCPR, with bigger free energy differences between the diastereoisomeric transition states. The value of $\Delta \Delta \mathrm{G}^{\ddagger} \mathrm{UB3LYP}$ of $2.3 \mathrm{kcal} \mathrm{mol}^{-1}$ corresponds to a kinetic ratio of $37: 38$ of $>20: 1$, which would predict that cis-product $\mathbf{3 8}$ would not be detected in product mixtures by ${ }^{19} \mathrm{~F}$ NMR. Table 6 summarises the outcomes using the two methods.

The other four transition states from the set started from the Z-alkenoate; only one (TS39d) of the four optimised to a geometry recognisable as a VCPR transition state, $34.7 \mathrm{kcal}$ $\mathrm{mol}^{-1}$ above 34a ( $\Delta \mathrm{G}^{\ddagger}$ UM05-2X), so there is only one pair of diastereoisomeric structures related by opposite alkene configurations.

Table 5. Relative free energies (G, gas phase, $298 \mathrm{~K}$ kcal mol$\left.{ }^{-1}\right)$ for cyclopropanes $(\mathbf{2 9}, \mathbf{3 4})$, ring-opened triplets $(\mathbf{3 2}$, $35)$ and triplet interconversion transition states $(33,36)$.

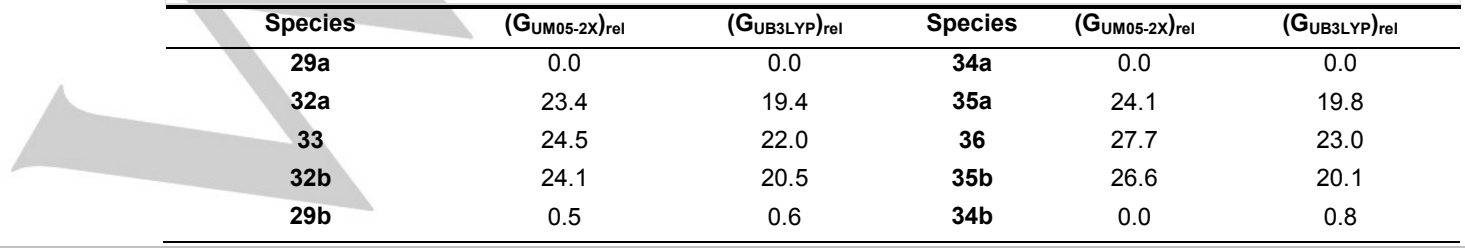


Table 6. Barriers $\left(\Delta \mathrm{G}^{\ddagger}\right.$, gas phase, $\left.298 \mathrm{~K}, \mathrm{kcal} \mathrm{mol}^{-1}\right)$ for $\mathrm{VCPR}$ from diastereoisomeric transition states.

\begin{tabular}{ccc}
\hline TS & $\Delta \mathbf{G}^{\ddagger}$ UM05-2X & $\Delta \mathbf{G}^{\ddagger}$ UB3LYP \\
\hline TS29a & 29.8 & 25.9 \\
TS29b & 30.8 & 26.6 \\
TS29c & 30.1 & 28.2 \\
TS29d & 30.8 & 28.9 \\
TS39d & 34.7 & 32.8 \\
\hline
\end{tabular}

The other four transition states from the set started from the Z-alkenoate; only one (TS39d) of the four optimised to a geometry recognisable as a VCPR transition state, $34.7 \mathrm{kcal}$ $\mathrm{mol}^{-1}$ above 34a $\left(\Delta \mathrm{G}^{\ddagger} u\right.$ Mo5-2X), so there is only one pair of diastereoisomeric structures related by opposite alkene configurations. The additional cost of access to this structure may arise from close approach (2.65 $\AA$ ) between the benzylic proton and the alkenoate carbonyl carbon. When the ester was posed in the alternate $s$-trans syn conformation, a different $(6,5$ bicyclic) ring closure with a very high barrier $\left(\Delta G^{\ddagger} \cup\right.$ M05-2X $=55.2$ $\mathrm{kcal} \mathrm{mol}{ }^{-1}$ ) was indicated.
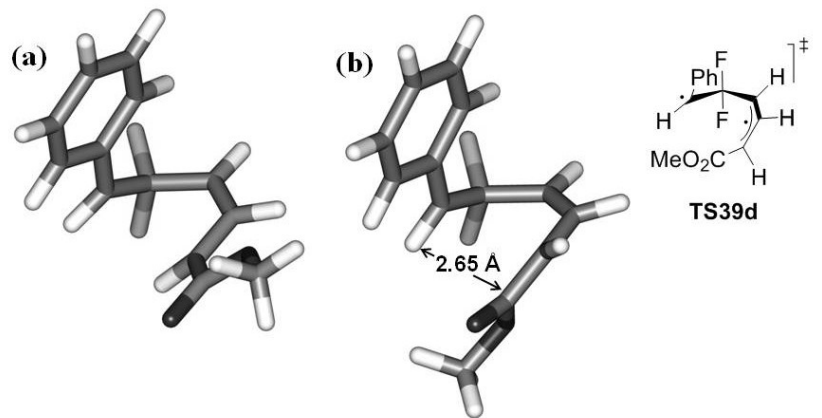

Figure 8. Alkene diastereoisomeric transition structures, both with s-trans, syn alkenoate conformation: (a) TS29d from $E$-alkenoate series $\left(\Delta G^{\ddagger} U\right.$ M05-2X $=30.8$ kcal mol ${ }^{-1}$ and $\Delta G^{\ddagger}$ UB3LYP $=28.9 \mathrm{kcal} \mathrm{mol}^{-1}$ ); (b) TS39d from Z-alkenoate series $\left(\Delta \mathrm{G}^{\ddagger}{ }_{\mathrm{UMM} 05-2 \mathrm{X}}=34.7 \mathrm{kcal} \mathrm{mol}^{-1}\right.$ and $\left.\Delta \mathrm{G}^{\ddagger}{ }_{\text {UB } 3 L Y P}=32.8 \mathrm{kcal} \mathrm{mol}^{-1}\right)$ showing the H...C close contact.

The two alternate transition structures failed to optimise to structures which corresponded to VCPR. Figure 8 shows the pair of transition structures (TS29d and TS39d) which differ only in the alkene configuration and thus lead to cis and trans products respectively. These transition structures lie 30.8 and $34.7 \mathrm{kcal} \mathrm{mol}^{-1}$ respectively above their precursors from the UM05-2X data, and 28.9 and $32.8 \mathrm{kcal} \mathrm{mol}^{-1}$ respectively above their precursors from UB3LYP, showing the higher cost $(3.9 \mathrm{kcal}$ $\mathrm{mol}^{-1}$ with both methods) of rearrangement from the Z-series.

The concerted [3,3]-rearrangement pathway was examined for the formation of the benzocycloheptadienes from the cis-cyclopropanes; from M05-2X calculations, the cis- $E$ TS 40 lies $27.7 \mathrm{kcal} \mathrm{mol}^{-1}$ above precursor $29 \mathrm{~b}$; cis-Z TS 41 has a higher barrier at $34.7 \mathrm{kcal} \mathrm{mol}^{-1}$ above the cis-Z precursor $34 \mathrm{~b}$ (Figure 9). The corresponding values from the B3LYP calculations were 27.8 and $32.9 \mathrm{kcal} \mathrm{mol}^{-1}$ respectively.<smiles>COC(=O)c1cc2ccccc2cc1C(F)(F)F</smiles>

40<smiles>CC(=O)C1C=CC(F)=Cc2ccccc21</smiles>

43a
41 42<smiles>COC(=O)C1=CCC(F)=Cc2ccccc21</smiles>

43c<smiles>COC(=O)C=Cc1cc(C(F)(F)F)cc2ccccc12</smiles>

Figure 9. Initial (42) and final (43a-c) [3,3]-rearrangement products and transition states $(\mathbf{4 0}, \mathbf{4 1})$ from cis-cyclopropanes.

There is an eclipsing interaction between a $\mathrm{C}-\mathrm{H}$ bond and a $\mathrm{C}-\mathrm{C}$ bond in 41, which results in the higher barrier. Once again, the alkene configuration has a decisive effect on reactivity, consistent with the experimental observations in which the Zspecies only reacted at significantly higher temperature.

The immediate product $\mathbf{4 2}$ has lost aromaticity and therefore lies above precursor $29 \mathrm{~b}$; $\left(\left(\mathrm{G}_{\mathrm{M} 05-2 \mathrm{X}}\right)_{\mathrm{rel}} 9.3 \mathrm{kcal} \mathrm{mol}^{-1},\left(\mathrm{G}_{\mathrm{B} 3 L \mathrm{YP}}\right)_{\mathrm{rel}}=\right.$ $14.5 \mathrm{kcal} \mathrm{mol}^{-1}$ ) loss of HF leads to 43a-c. Both sets of calculations identified thermodynamic product $43 \mathrm{~b}$ correctly (for 43a $\left(G_{\text {M05-2X }}\right)_{\text {rel }}-19.0 \mathrm{kcal} \mathrm{mol}^{-1},\left(G_{\text {BзLYP }}\right)_{\text {rel }}=-9.4 \mathrm{kcal} \mathrm{mol}^{-1}$; for 43b $\left(G_{\text {MO5-2X }}\right)_{\text {rel }}-22.8 \mathrm{kcal} \mathrm{mol}^{-1}$, $\left(G_{\text {BзLYP }}\right)_{\text {rel }}=-14.5 \mathrm{kcal} \mathrm{mol}^{-1}$; for 43c $\left.\left(G_{\text {M05-2X }}\right)_{\text {rel }}-19.6 \mathrm{kcal} \mathrm{mol}^{-1},\left(G_{B 3 L Y P}\right)_{\text {rel }}=-11.1 \mathrm{kcal} \mathrm{mol}^{-1}\right)$. Overall, the VCPR reactions to $37\left(\left(\mathrm{G}_{\text {MO5-2x }}\right)_{\text {rel }}-26.8 \mathrm{kcal} \mathrm{mol}^{-1}\right.$, $\left.\left(G_{\text {BзLYP }}\right)_{\text {rel }}=-21.1 \mathrm{kcal} \mathrm{mol}^{-1}\right)$ and $38\left(\left(G_{\text {M05-2X }}\right)_{\text {rel }}-26.8 \mathrm{kcal} \mathrm{mol}^{-1}\right.$, $\left.\left(G_{B 3 L Y P}\right)_{\text {rel }}=-18.4 \mathrm{kcal} \mathrm{mol}^{-1}\right)$ were strongly exergonic from precursors $29 \mathrm{a}$ and $29 \mathrm{~b}$ respectively.

Our initial interest in carrying out electronic structure calculations based on this set of reactions arose from a wish to order the reactivities of the competing pathways successfully; cis/trans cyclopropane stereoisomerisation, stereoselective trans-cyclopentene formation by VCPR, [3,3]-rearrangement versus VCPR and the low reactivity of Z-alkenoates versus the $E$-diastereoisomers all required explanation. The two computational methods selected deal with these questions differently, as summarised in Table 7.

Table 7. Barriers $\left(\Delta G^{\ddagger}\right)$ and differences $\left(\Delta \Delta G^{\ddagger}\right)$ between barriers (gas phase, $298 \mathrm{~K}, \mathrm{kcal} \mathrm{mol}^{-1}$ ) relating to selectivities between isomerisation, VCPR and [3,3]-rearrangement pathways.

\begin{tabular}{|c|c|c|}
\hline Pathway/process & M05-2X & B3LYP \\
\hline Cyclopropane isomerisation $\mathbf{2 9} a / 29 b, \Delta G^{\ddagger}$ & 24.5 & 22.0 \\
\hline Cyclopropane isomerisation $\mathbf{3 4 a} / \mathbf{3 4 b}, \Delta \mathrm{G}^{\ddagger}$ & 27.7 & 23.0 \\
\hline Lowest cost VCPR, $\Delta \mathrm{G}^{\ddagger}$ & 29.8 & 25.9 \\
\hline Lowest cost [3,3]-rearrangement from $29 b, \Delta G^{\ddagger}$ & 27.7 & 27.8 \\
\hline $\begin{array}{l}\text { Selectivity for formation of kinetic trans-product, } \\
\mathbf{3 7} \text { versus } \mathbf{3 8}, \Delta \Delta \mathrm{G}^{\ddagger}\end{array}$ & 0.3 & 2.3 \\
\hline$E$ versus $Z$ selectivity for $\mathrm{VCPR}, \Delta \Delta \mathrm{G}^{\ddagger}$ & 5.5 & 3.9 \\
\hline $\begin{array}{l}E \text { versus } Z \text { selectivity for }[3,3] \text {-rearrangement, } \\
40 \text { versus } 41, \Delta \Delta G^{\ddagger}\end{array}$ & 7.0 & 5.1 \\
\hline
\end{tabular}


Of the two methods used, UB3LYP/6-31G* (with B3LYP/6$31 \mathrm{G}^{*}$ for the closed shell systems) orders the pathways correctly by reactivity, predicts the stereoselectivity of the VCPR in agreement with experiment and rationalises the effect of alkene configuration on VCPR and [3,3]-rearrangement rates. While the UM05-2X/6-31+G* method provided the highest accuracy at lowest cost for the VCPR test set, the agreement between predicted and experimental reactivity order suggests strongly that the older UB3LYP/6-31G* method may prove most effective for triage of new synthetic reactions.

\section{Conclusions}

We have developed a synthetic route which allows access to all four isomers of ethyl 3-(1'(2'2'-difluoro-3'-phenyl)cyclopropyl) propenoate from commercially available precursors using Dolbier's robust and effective difluorocarbene transfer reagent MDFA. Cyclopropane stereoisomerisation was facile at $100{ }^{\circ} \mathrm{C}$ in toluene and this process was followed with VCPR by ${ }^{19} \mathrm{~F} \mathrm{NMR}$ spectroscopy. The trans- $E$ isomer (18a) was synthetically easiest to access and rearranged to difluorocyclopentene 23 in close to quantitative yield. The overall yield of 23 over four steps from cinnamyl acetate was $70 \%$. Our results show clearly that the alkene configuration controls which rearrangement pathway is followed; E-isomers underwent VCPR whereas [3,3]rearrangement was more favourable for Z-isomers. While the UM05-2X/6-31+G* method provided the highest accuracy at lowest cost for the VCPR test set, the agreement between predicted and experimental reactivity order suggests strongly that the older UB3LYP/6-31G* method may prove most effective for triage of new synthetic reactions.

Work is currently underway to design and access more complex difluorocyclopentenes using a combination of computational triage and synthetic chemistry.

\section{Experimental Section}

Screening of other difluorocarbene sources, experimental procedures and spectral data for all new compounds, selected intermediates and crude products, kinetic raw data, simulation data and Arrhenius plot, summary of computational energies and Cartesian coordinates (B3LYP/6-31G* and M05-2X/6-31+G* optimised structures) are provided in Supporting Information.

General Experimental: NMR spectra were recorded on Bruker DPX-400 and AV-500 spectrometers. ${ }^{1} \mathrm{H},{ }^{19} \mathrm{~F}$ and ${ }^{13} \mathrm{C}$ NMR spectra were recorded using the deuterated solvent as the lock and the residual solvent as the internal reference. The multiplicities of the spectroscopic data are presented in the following manner: $s=$ singlet, $d=$ doublet, $d d=$ double doublet, ddd $=$ doublet of doublet doublets, dddd $=$ doublet of doublet of doublet of doublets; $\mathrm{dt}=$ doublet of triplets, $\mathrm{ddt}=$ doublet of double triplets, $\mathrm{dtd}=$ doublet of triple doublets, $\mathrm{t}=$ triplet, $\mathrm{tdd}=$ triplet of double doublets, $\mathrm{q}=$ quartet, $\mathrm{m}=$ multiplet and br. = broad. Unless stated otherwise, all couplings refer to ${ }^{3} \mathrm{~J}$ homocouplings. All ${ }^{1} \mathrm{H}$ spectra are fully assigned. IR spectra were recorded on an ATR IR spectrometer. GC/MS spectra were obtained on an instrument fitted with a DB5-type column $(30 \mathrm{~m} \times 0.25 \mu \mathrm{m})$ running a $40-320{ }^{\circ} \mathrm{C}$ temperature program, ramp rate $20{ }^{\circ} \mathrm{C} \mathrm{min}{ }^{-1}$ with helium carrier gas flow at $1 \mathrm{~cm}^{3} \mathrm{~min}^{-1}$. Chemical ionisation $(\mathrm{Cl})$ (methane) mass spectra were recorded on an Agilent
Technologies 5975C mass spectrometer. HRMS measurements were obtained from a Thermofisher LTQ Orbitrap XL (APCI) or Finnigan MAT 95 XP (EI) spectrometers (EPSRC National Mass Spectrometry Service Centre, Swansea). Thin layer chromatography was performed on precoated aluminium-backed silica gel plates (E.Merck, A.G.Darmstadt, Germany. Silica gel 60 F254, thickness $0.2 \mathrm{~mm}$ ). Visualisation was achieved using potassium permanganate or UV detection at $254 \mathrm{~nm}$. Column chromatography was performed on silica gel (Zeochem, Zeoprep 60 HYD, 40-63 $\mu \mathrm{m}$ ) using a Büchi Sepacore system. Hexane was distilled before chromatography. All glassware used in the synthesis of methyl(trifluoromethyl)dioxirane was washed with an aqueous solution of ethylenediaminetetraacetic acid $(0.1 \mathrm{M})$ to removed trace metals and then oven dried $\left(150^{\circ} \mathrm{C}\right)$ before use. Diglyme was distilled from $\mathrm{CaH}_{2}$ $\left(60{ }^{\circ} \mathrm{C} / 23 \mathrm{mbar}\right.$ ) and stored under nitrogen over $\mathrm{CaH}_{2}$. Trimethylsilyl chloride was distilled from $\mathrm{CaH}_{2}\left(60{ }^{\circ} \mathrm{C} / 430 \mathrm{mbar}\right)$ and stored under nitrogen over $\mathrm{CaH}_{2}$ in the refrigerator. Methyl 2,2-Difluoro-2(fluorosulfonyl)acetate (MDFA) was purchased from Fluorochem and stored under a headspace of nitrogen. Potassium iodide (Sigma Aldrich) was dried in the oven $\left(150{ }^{\circ} \mathrm{C}\right.$ ) before use. DCM (for oxidation/Wittig reactions) was dried using a PureSolv system from Innovative Technology, Inc.. All other chemicals were purchased from Sigma Aldrich, Apollo Scientific, Alfa Aesar, or Fluorochem and used as received.

Preparation of 10: An oven dried two-necked round bottom flask containing potassium iodide $(3.68 \mathrm{~g}, 22.2 \mathrm{mmol})$ was sealed with a SubaSeal, and the salt was stirred and lightly flame dried under an atmosphere of argon. A low boiling point water condenser with a gas outlet connected to an argon/vacuum manifold was attached and the reaction flask and the atmosphere were purged three times. Cinnamyl acetate $9(1.34 \mathrm{~mL}, 8.0 \mathrm{mmol})$ followed by diglyme $(1.3 \mathrm{~mL})$ were added and the yellow suspension was heated to $120{ }^{\circ} \mathrm{C}$. Once the reaction temperature had been reached, TMSCl $(2.6 \mathrm{~mL}, 19.7 \mathrm{mmol})$ and MDFA $(2.6 \mathrm{~mL}, 19.7 \mathrm{mmol})$ were added dropwise in that order. After 5 hours, the reaction mixture had evaporated to dryness and a further portion of diglyme $(1.3 \mathrm{~mL})$ was added. The mixture was stirred for a further 19 hours (total reaction time of 24 hours). The resulting brown solution was cooled to room temperature and the reaction mixture was quenched with aqueous $\mathrm{NaCl}(10 \mathrm{~mL})$ and diethyl ether $(10 \mathrm{~mL})$ added. The organic layer was separated and the aqueous layer was extracted with diethyl ether $(2 \times 10 \mathrm{~mL})$. The original organic layer and the extracts were combined, dried $\left(\mathrm{MgSO}_{4}\right)$ and concentrated under reduced pressure to remove volatiles. The ${ }^{1} \mathrm{H}$ NMR spectrum of the resulting brown oil confirmed full conversion. Column chromatography on silica gel (2:23 diethyl ether in hexane) afforded acetate 10 as a pale yellow oil (1.7 g, $94 \%) . \mathrm{R}_{\mathrm{f}}=0.26\left(1: 9\right.$ diethyl ether/hexane); ${ }^{1} \mathrm{H}$ NMR $\left(400 \mathrm{MHz}, \mathrm{CDCl}_{3}\right): \delta$ = 7.36-7.29 (m, ArH, 3H), 7.23-7.21 (br. d, J = 7.9 Hz, ArH, 2H), $4.38(\mathrm{br}$. ddd, $J=11.9,{ }^{4} J=2.5$ and $1.0 \mathrm{~Hz}, \mathrm{CH}_{a} \mathrm{H}_{\mathrm{b}} \mathrm{OAc}, 1 \mathrm{H}$ ), 4.25 (br. dd, $J=7.8$ ${ }^{4} \mathrm{~J}=1.6 \mathrm{~Hz}, \mathrm{CH}_{\mathrm{a}} \mathrm{H}_{b} \mathrm{OAc}, 1 \mathrm{H}$ ), 2.68 (dd, $J_{\mathrm{H}-\mathrm{F}}=14.5 \mathrm{~Hz}, J=7.8 \mathrm{~Hz}, \mathrm{PhCH}$, $1 \mathrm{H}), 2.33-2.24\left(\mathrm{~m}, \mathrm{C}(\mathrm{H}) \mathrm{CH}_{2} \mathrm{OAc}, 1 \mathrm{H}\right), 2.10 \mathrm{ppm}\left(\mathrm{s}, \mathrm{OC}(\mathrm{O}) \mathrm{CH}_{3}, 3 \mathrm{H}\right) ;{ }^{13} \mathrm{C}$ NMR $\left(100 \mathrm{MHz}, \mathrm{CDCl}_{3}\right): \delta=170.9,132.7,128.6,128.2,127.5,113.1(\mathrm{t}$, $\left.{ }^{1} J_{\mathrm{C}-\mathrm{F}}=289.4 \mathrm{~Hz}\right), 60.9\left(\mathrm{~d}, J_{\mathrm{C}-\mathrm{F}}=5.6 \mathrm{~Hz}\right), 32.0\left(\mathrm{t},{ }^{2} J_{\mathrm{C}-\mathrm{F}}=11.2 \mathrm{~Hz}\right), 28.0(\mathrm{t}$ $\left.{ }^{2} J_{\mathrm{C}-\mathrm{F}}=10.3 \mathrm{~Hz}\right), 20.8 \mathrm{ppm} ;{ }^{19} \mathrm{~F} \mathrm{NMR}\left(376 \mathrm{MHz} \mathrm{CDCl}_{3}\right): \delta=-135.4(\mathrm{dd}$, $\left.{ }^{2} \mathrm{~J}=157.8 \mathrm{~Hz}, J_{\mathrm{F}-\mathrm{H}}=14.5 \mathrm{~Hz}, \mathrm{C} F_{\mathrm{a}} \mathrm{F}_{\mathrm{b}}, 1 \mathrm{~F}\right),-137.3 \mathrm{ppm}\left(\mathrm{dd},{ }^{2} \mathrm{~J}=158.6 \mathrm{~Hz}\right.$, $\left.J_{\mathrm{F}-\mathrm{H}}=14.0 \mathrm{~Hz}, \mathrm{CF}_{\mathrm{a}} F_{b}, 1 \mathrm{~F}\right) ; \bar{v} /(\mathrm{film})=2386,2354,1737,1225,1017,999$, 972, $696 \mathrm{~cm}^{-1}$; MS (Cl): $\mathrm{m} / \mathrm{z}(\%): 167$ (55) [M-OAc] ${ }^{+}, 147$ (100); HRMS (EI): calcd for $\mathrm{C}_{12} \mathrm{H}_{12} \mathrm{~F}_{2} \mathrm{O}_{2}, 226.0800$ [M], found 226.0861; $\mathrm{t}_{\mathrm{R}}(\mathrm{GC})=11.37$ minutes. The data was in agreement with that reported by Kobayashi and co-workers but no ${ }^{13} \mathrm{C}$ NMR data was reported. ${ }^{81,82}$

Preparation of 11: A solution of potassium carbonate $(443 \mathrm{mg}, 3.2$ $\mathrm{mmol})$ in $\mathrm{H}_{2} \mathrm{O}(2 \mathrm{~mL})$ was added to a solution of acetate $10(718.7 \mathrm{mg}$, $3.2 \mathrm{mmol})$ in $\mathrm{MeOH}(60 \mathrm{~mL}, 0.05 \mathrm{M})$ and the mixture was heated to $60{ }^{\circ} \mathrm{C}$ for 1 hour. Full conversion was confirmed by TLC. The reaction mixture was concentrated under reduced pressure and the resulting suspension taken up in $\mathrm{MeOH}(5 \mathrm{~mL})$ and evaporated onto Celite $(6.4 \mathrm{~g})$. The solid 
was transferred onto a sinter funnel and the product was eluted with diethyl ether $(60 \mathrm{~mL})$. The filtrate was concentrated under reduced pressure to afford alcohol 11 as a colourless oil (583.5 mg, 99\%). Compound was of a high analytical standard that no purification was required (corresponding NMR data on pages S22-S25). $R_{f}=0.16(1: 4$ diethyl ether/hexane); ${ }^{1} \mathrm{H}$ NMR (400 MHz, $\left.\mathrm{CDCl}_{3}\right): \delta=7.38-7.30(\mathrm{~m}, \mathrm{ArH}$, $3 \mathrm{H}$ ), 7.27-7.25 (m, $\mathrm{ArH}, 2 \mathrm{H}), 4.01-3.86$ (br. m, $\mathrm{CH}_{2} \mathrm{OH}, 2 \mathrm{H}$ ), 2.65 (ddd, $\left.J_{\mathrm{H}-\mathrm{F}}=13.5, \mathrm{~J}=7.6,{ }^{4} \mathrm{~J}=1.4 \mathrm{~Hz}, \mathrm{PhCH}, 1 \mathrm{H}\right), 2.23\left(\mathrm{~m}, \mathrm{CHCH}_{2} \mathrm{OH}, 1 \mathrm{H}\right)$, $1.72 \mathrm{ppm}\left(\mathrm{t}, J=5.9 \mathrm{~Hz}, \mathrm{CH}_{2} \mathrm{OH}, 1 \mathrm{H}\right) ;{ }^{13} \mathrm{C} \mathrm{NMR}\left(100 \mathrm{MHz}, \mathrm{CDCl}_{3}\right): \delta=$ 132.5, 128.1, 127.6, 126.8, $113.9\left(\mathrm{t},{ }^{1} J_{\mathrm{C}-\mathrm{F}}=289.1 \mathrm{~Hz}\right), 59.3\left(\mathrm{~d}, J_{\mathrm{C}-\mathrm{F}}=5.5\right.$ $\mathrm{Hz}), 31.0\left(\mathrm{t},{ }^{2} J_{\mathrm{C}-\mathrm{F}}=10.7 \mathrm{~Hz}\right), 30.7 \mathrm{ppm}\left(\mathrm{t},{ }^{2} \mathrm{~J}_{\mathrm{C}-\mathrm{F}}=9.6 \mathrm{~Hz}\right) ;{ }^{19} \mathrm{~F}$ NMR $(376$ $\left.\mathrm{MHz}, \mathrm{CDCl}_{3}\right): \delta=-136.2\left(\mathrm{dd},{ }^{2} \mathrm{~J}=158.1 \mathrm{~Hz}, J_{\mathrm{F}-\mathrm{H}}=14.0 \mathrm{~Hz}, 1 \mathrm{~F}\right),-136.9$ ppm (dd, $\left.{ }^{2} J=157.6 \mathrm{~Hz}, J_{\mathrm{F}-\mathrm{H}}=13.5 \mathrm{~Hz}, 1 \mathrm{~F}\right) ; \bar{v} /($ film) $=3321$ (br.), 1500 , 1474, 1447, 1269, 1013, $698 \mathrm{~cm}^{-1}$; MS (Cl): $\mathrm{m} / \mathrm{z}(\%): 185(4)[\mathrm{M}+\mathrm{H}]^{+}, 167$ (21) $[\mathrm{M}-\mathrm{OH}], 147$ (100) [(M+H)-F $]^{+}$, HRMS (APCl): calcd for $\mathrm{C}_{10} \mathrm{H}_{10} \mathrm{~F}_{2} \mathrm{O}$, $184.0694[\mathrm{M}-\mathrm{H}]^{+}$, found 184.0688; $t_{R}(\mathrm{GC})=10.56$ minutes. Alcohol 11 has been reported in the literature but no characterisation data was reported. ${ }^{82}$ The compound was also reported recently by Itoh and coworkers ${ }^{55}$ though the material isolated was of lower quality than that used in our study.

Preparation of 18a/18b: Bis(acetoxy)iodobenzene (1.35g, $4.23 \mathrm{mmol})$ was added to a solution of alcohol $11(678 \mathrm{mg}, 3.68 \mathrm{mmol})$ and TEMPO (54 $\mathrm{mg}, 0.368 \mathrm{mmol})$ in anhydrous $\mathrm{DCM}(15 \mathrm{~mL})$ and the reaction mixture was stirred at room temperature under nitrogen for 6 hours. The ${ }^{1} \mathrm{H} \quad$ NMR spectrum showed complete conversion to the corresponding aldehyde. (Ethoxycarbonylmethylene)triphenylphosphorane $(1.64 \mathrm{~g}, 4.7 \mathrm{mmol})$ was then added to the reaction mixture and stirred for 2 hours until the ${ }^{1} \mathrm{H}$ or ${ }^{19} \mathrm{~F}$ NMR spectrum showed complete conversion. The resulting orange solution was concentrated under reduced pressure and column chromatography on silica gel (1:19 diethyl ether in hexane) afforded 18a (728 mg, 78\%) and 18b (43 mg, 5\%). Data for 18a: $R_{f}=0.30$ (1:9 diethyl ether/hexane); ${ }^{1} \mathrm{H}$ NMR (500 MHz, $\left.\mathrm{CDCl}_{3}\right): \delta=7.40-7.31(\mathrm{~m}, \mathrm{ArH}, 3 \mathrm{H})$, 7.27-7.25 (m, ArH, 2H), 6.79 (ddt, $J=15.6,9.5 \mathrm{~Hz},{ }^{4} J_{\mathrm{H}-\mathrm{F}}=1.5 \mathrm{~Hz}$, $\left.\mathrm{HC}=\mathrm{CHCO}_{2} \mathrm{Et}, 1 \mathrm{H}\right), 6.09\left(\mathrm{~d}, \mathrm{~J}=15.6 \mathrm{~Hz}, \mathrm{HC}=\mathrm{CHCO}_{2} \mathrm{Et}, 1 \mathrm{H}\right), 4.25$ (q, J = $7.2 \mathrm{~Hz}, \mathrm{CO}_{2} \mathrm{CH}_{2} \mathrm{CH}_{3}, 2 \mathrm{H}$ ), 2.91 (dd, $J_{\mathrm{H}-\mathrm{F}}=14.7 \mathrm{~J}=7.3 \mathrm{~Hz}, \mathrm{PhCH}, 1 \mathrm{H}$ ), 2.66-2.60 (ddd, $\left.J_{\mathrm{H}-\mathrm{F}}=13.4 \mathrm{~J}=9.5,7.3 \mathrm{~Hz}, \mathrm{CHCH}=\mathrm{CH}, 1 \mathrm{H}\right), 1.33 \mathrm{ppm}(\mathrm{t}$, $\left.J=7.2 \mathrm{~Hz}, \mathrm{CO}_{2} \mathrm{CH}_{2} \mathrm{CH}_{3}, 3 \mathrm{H}\right) ;{ }^{13} \mathrm{C}$ NMR $\left(100 \mathrm{MHz}, \mathrm{CDCl}_{3}\right): \delta=165.0$, $139.8,131.8,128.2,127.4,127.2,123.2,112.9\left(\mathrm{t},{ }^{1} J_{\mathrm{C}-\mathrm{F}}=292.6 \mathrm{~Hz}\right), 59.9$ $35.4\left(\mathrm{t},{ }^{2} J_{\mathrm{C}-\mathrm{F}}=9.8 \mathrm{~Hz}\right) 33.1\left(\mathrm{t},{ }^{2} J_{\mathrm{C}-\mathrm{F}}=12.7 \mathrm{~Hz}\right), 13.7 \mathrm{ppm} ;{ }^{19} \mathrm{~F}$ NMR $(376$ $\left.\mathrm{MHz}, \mathrm{CDCl}_{3}\right): \delta=130.6\left(\mathrm{dd},{ }^{2} \mathrm{~J}=157.4 \mathrm{~Hz}, J_{\mathrm{F}-\mathrm{H}}=14.7 \mathrm{~Hz}, 1 \mathrm{~F}\right),-135.6$ ppm (dd, $\left.{ }^{2} J=156.6 \mathrm{~Hz}, J_{\mathrm{F}-\mathrm{H}}=13.4 \mathrm{~Hz}, 1 \mathrm{~F}\right) ; \bar{v} /($ film $)=2359,2342,1715$, $1281 \mathrm{~cm}^{-1}$; MS (Cl): m/z (\%): 233 (100) [M-F], 187 (44), 159 (26); HRMS (APCI): calcd for $\mathrm{C}_{14} \mathrm{H}_{15} \mathrm{~F}_{2} \mathrm{O}_{2}, 253.1035[\mathrm{M}+\mathrm{H}]^{+}$, found 253.1034; $\mathrm{t}_{\mathrm{R}}(\mathrm{GC})$ $=12.13$ minutes. Data for $18 \mathrm{~b}: \mathrm{R}_{\mathrm{f}}=0.43$ (1:9 ethyl acetate/hexane); ${ }^{1} \mathrm{H}$ NMR (400 MHz CDCl 3$): \delta=7.40-7.29(\mathrm{~m}, \mathrm{ArH}, 5 \mathrm{H}), 6.06-5.99(\mathrm{~m}$, $\left.\mathrm{HC}=\mathrm{CHCO}_{2} \mathrm{Et}, 2 \mathrm{H}\right), 4.234\left(\mathrm{q}, J=7.2 \mathrm{~Hz}, \mathrm{OCH}_{a} \mathrm{H}_{\mathrm{b}} \mathrm{CH}_{3}, 1 \mathrm{H}\right), 4.225$ (q, J = $\left.7.2 \mathrm{~Hz}, \mathrm{OCH}_{\mathrm{a}} \mathrm{H}_{b} \mathrm{CH}_{3}, 1 \mathrm{H}\right), 4.18-4.10\left(\mathrm{~m}, \mathrm{HCCH}=\mathrm{CHCO}_{2} \mathrm{Et}, 1 \mathrm{H}\right), 2.84$ (dd, $\left.J_{\mathrm{H}-\mathrm{F}}=14.8 \mathrm{~Hz}, J=7.1 \mathrm{~Hz}, \mathrm{CHPh}, 1 \mathrm{H}\right), 1.32 \mathrm{ppm}\left(\mathrm{t}, J=7.2 \mathrm{~Hz}, \mathrm{CH}_{3}, 3 \mathrm{H}\right)$; ${ }^{13} \mathrm{C}$ NMR $\left(100 \mathrm{MHz}_{\mathrm{CDCl}}\right): \delta=165.7,140.1\left(\mathrm{~d}, \mathrm{~J}_{\mathrm{C}-\mathrm{F}}=6.3 \mathrm{~Hz}\right), 131.7$, 128.1, 127.7, 127.1, 121.3, $113.5\left(\mathrm{t},{ }^{1} J_{\mathrm{C}-\mathrm{F}}=291.1 \mathrm{~Hz}\right), 59.8,36.2\left(\mathrm{dd},{ }^{2} J_{\mathrm{C}}\right.$ $\mathrm{F}=11.8,9.1 \mathrm{~Hz}), 30.1\left(\mathrm{dd},{ }^{2} J_{\mathrm{C}-\mathrm{F}}=13.6,9.9 \mathrm{~Hz}\right), 13.7 \mathrm{ppm} ;{ }^{19} \mathrm{~F}$ NMR $(376$ $\left.\mathrm{MHz}, \mathrm{CDCl}_{3}\right): \delta=-132.3\left(\mathrm{dd},{ }^{2} \mathrm{~J}=154.3 \mathrm{~Hz} \mathrm{~J}_{\mathrm{F}-\mathrm{H}}=14.8 \mathrm{~Hz}, 1 \mathrm{~F}\right),-136.2$ ppm (dd, $\left.{ }^{2} J=154.6 \mathrm{~Hz} J_{\mathrm{F}-\mathrm{H}}=13.7 \mathrm{~Hz}, 1 \mathrm{~F}\right) ; \bar{v} /(\mathrm{film})=2359,2342,1715$, 1194, 1018, $806 \mathrm{~cm}^{-1}$; MS (Cl): $\mathrm{m} / \mathrm{z}(\%): 281$ (4) $\left[\mathrm{M}+\mathrm{C}_{2} \mathrm{H}_{5}\right]^{+}, 253$ (70) $[\mathrm{M}+\mathrm{H}]^{+}, 233(35)[\mathrm{M}-\mathrm{F}], 225(36), 205(60)[(\mathrm{M}+\mathrm{H})-(\mathrm{F}+\mathrm{Et})]^{+}, 187(100)$ 179 (30) $\left[\mathrm{M}-\mathrm{CO}_{2} \mathrm{Et}\right], 169$ (18) $\left[\mathrm{M}-\mathrm{F}_{2}+\mathrm{OEt}\right], 159$ (45), 141 (28) [M$\mathrm{F}_{2}+\mathrm{CO}_{2} \mathrm{Et}$; HRMS (APCI): calcd for $\mathrm{C}_{14} \mathrm{H}_{15} \mathrm{~F}_{2} \mathrm{O}_{2}, 253.1035[\mathrm{M}+\mathrm{H}]^{+}$, found 253.1035; $t_{R}(G C)=12.36$ minutes

Preparation of 23: A solution of $18 \mathrm{a}(104 \mathrm{mg}, 0.4 \mathrm{mmol})$ in toluene $(0.5$ $\mathrm{mL}$ ) was heated to $100{ }^{\circ} \mathrm{C}$ in a sealed microwave vial for 17 hours in a DrySyn block. After cooling and venting the vial, fluorine NMR confirmed complete conversion. The reaction mixture was transferred to a round bottom flask using DCM $(5 \mathrm{~mL})$ and concentrated under reduced pressure to afford difluorocyclopentene $23(102 \mathrm{mg}, 99 \%)$ as a pale yellow oil. $R_{f}=0.34$ (1:4 diethyl ether/hexane); ${ }^{1} \mathrm{H}$ NMR (400 MHz, $\left.\mathrm{CDCl}_{3}\right): \delta=7.41-7.33(\mathrm{~m}, \mathrm{ArH}, 5 \mathrm{H}), 6.50\left(\mathrm{dt}, J=6.0,{ }^{4} J_{\mathrm{H}-\mathrm{F}}=1.6 \mathrm{~Hz}\right.$, $\left.=\mathrm{CHCO}_{2} \mathrm{Et}, 1 \mathrm{H}\right), 6.09\left(\mathrm{dd}, J=6.0, J_{\mathrm{H}-\mathrm{F}}=2.5 \mathrm{~Hz},=\mathrm{CHCF}_{2}, 1 \mathrm{H}\right), 4.18(\mathrm{q}, J$ $\left.=7.1 \mathrm{~Hz}, \mathrm{OCH}_{2} \mathrm{CH}_{3}, 2 \mathrm{H}\right), 4.04-3.92\left(\mathrm{~m}, \mathrm{CHCO}_{2} \mathrm{Et}, \mathrm{CHPh}, 2 \mathrm{H}\right), 1.26 \mathrm{ppm}$ (t, $\left.J=7.1 \mathrm{~Hz}, \mathrm{OCH}_{2} \mathrm{CH}_{3}, 3 \mathrm{H}\right) ;{ }^{13} \mathrm{C} \mathrm{NMR}\left(400 \mathrm{MHz}, \mathrm{CDCl}_{3}\right): \delta=170.3$ (d, $\left.{ }^{4} J_{\mathrm{C}-\mathrm{F}}=4.8 \mathrm{~Hz}\right), 138.6\left(\mathrm{t}, J_{\mathrm{C}-\mathrm{F}}=10.4 \mathrm{~Hz}\right), 133.8,129.3\left(\mathrm{t},{ }^{1} J_{\mathrm{C}-\mathrm{F}}=245.7 \mathrm{~Hz}\right)$, 128.7, $128.5\left(\mathrm{dd},{ }^{2} J_{\mathrm{C}-\mathrm{F}}=25.0,30.3 \mathrm{~Hz}\right), 128.0,127.3,61.0,54.1\left(\mathrm{~d}, J_{\mathrm{C}-\mathrm{F}}\right.$ $=6.0 \mathrm{~Hz}), 53.2\left(\mathrm{t},{ }^{2} \mathrm{~J}_{\mathrm{C}-\mathrm{F}}=24.6 \mathrm{~Hz}\right), 13.6 \mathrm{ppm} ;{ }^{19} \mathrm{~F} \mathrm{NMR}(376 \mathrm{MHz}$, $\mathrm{CDCl}_{3}$ ): $\delta=-89.3\left(\mathrm{ddd},{ }^{2} \mathrm{~J}=252.8 \mathrm{~Hz}, J_{\mathrm{F}-\mathrm{H}}=16.6,8.9 \mathrm{~Hz}, 1 \mathrm{~F}\right),-92.7 \mathrm{ppm}$ (ddd, $\left.{ }^{2} \mathrm{~J}=253.2 \mathrm{~Hz}, \mathrm{~J}_{\mathrm{F}-\mathrm{H}}=14.2,5.8 \mathrm{~Hz}, 1 \mathrm{~F}\right) ; \bar{v} /($ film $)=2359,2340,1732$, 1254, 1194, 1167, $698 \mathrm{~cm}^{-1}$; MS (Cl): $\mathrm{m} / \mathrm{z}(\%): 253(3)[\mathrm{M}+\mathrm{H}]^{+}, 233(100)$ [M-F], 215 (8), 187 (40), 159 (33); HRMS (APCI): calcd for $\mathrm{C}_{14} \mathrm{H}_{15} \mathrm{FO}_{2}$, $253.1035[\mathrm{M}+\mathrm{H}]^{+}$found $253.1033 ; \mathrm{t}_{\mathrm{R}}(\mathrm{GC})=12.13$ minutes

\section{Computational Methods}

Structures were built in Spartan'08 or Spartan'10 and Monte Carlo conformational searching was carried out using the MMFF94 molecular mechanics method. Relatively small sets of conformers (4 typically) were obtained and geometry optimisation calculations were carried out for all members of the sets using the UB3LYP functional (invoked using the keywords $\mathrm{MIX}$ and SCF=UNRESTRICTED, with CONVERGE deprecated). In cases where SCF convergence was difficult, the keyword NODIIS was used. The $6-31 \mathrm{G}^{*}$ basis set was used throughout and calculations were carried out in vacuo. Calculations were carried out on a Dell Precision T1500 (Intel i7 Quad Core, $2.93 \mathrm{GHz}$ ) with 8GB RAM, Microsoft Windows 7 OS 64-bit, or a Dell Precision T7500 (2 x Intel E5530 processors, four cores each, $2.40 \mathrm{GHz}$ ) with 24 GB RAM Debian GNU/Linux 5. Calculations using the M05-2X/6-31+G* method were carried out using Gaussian $09^{75}$ on cluster hardware. Full references for Spartan and Gaussian09 can be found in the Supporting Information.

\section{Acknowledgements}

We thank GSK (Dr Vipulkumar K. Patel) and the University of Strathclyde (studentship to D.O.), the EPRSC National Mass Spectrometry Service Centre, Swansea for accurate mass measurements, and Craig Irving (NMR Technician, University of Strathclyde) for assistance with NMR kinetic experiments.

Keywords: rearrangement $\cdot$ difluorocyclopentene $\cdot$ activation parameters $\bullet$ density functional calculations $\cdot$ stereoselectivity

[1] Neureiter, N. J. Org. Chem. 1959, 24, 2044

[2] Hudlicky, T.; Reed, J. W. Angew. Chem. Int. Ed. 2010, 49, 4864

[3] Goldschmidt, Z.; Crammer, B. Chem. Soc. Rev. 1988, 17, 229.

[4] Baldwin, J. E. Chem. Rev. 2003, 103, 1197.

[5] Overberger, C. G.; Borchert, A. E. J. Am. Chem. Soc. 1960, 82, 4896.

[6] Vogel, E. Angew. Chem. 1960, 72, 4

[7] Danheiser, R. L.; Martinez-Davila, C.; Morin, J. M. J. Org. Chem 1980, 45, 1340

[8] Zuo, G.; Louie, J. Angew. Chem. Int. Ed. 2004, 43, 2277.

[9] Wang, S. C.; Troast, D. M.; Conda-Sheridan, M.; Zuo, G.; LaGarde, D.; Louie, J.; Tantillo, D. J. J. Org. Chem. 2009, 74 7822

[10] Jiao, L.; Yu, Z.-X. J. Org. Chem. 2013, 78, 6842.

[11] Willcott, M. R.; Cargle, V. H. J. Am. Chem. Soc. 1967, 89, 723.

[12] Willcott, M. R.; Cargle, V. H. J. Am. Chem. Soc. 1969, 91, 4310.

[13] Ellis, R. J.; Frey, H. M. J. Chem. Soc. 1964, 5578.

[14] Wellington, C. A. J. Phys. Chem. 1962, 66, 1671

[15] Lewis, D. K.; Charney, D. J.; Kalra, B. L.; Plate, A.-M.; Woodard, M. H.; Cianciosi, S. J.; Baldwin, J. E. J. Phys. Chem. A 1997, $101,4097$. 
[16] Schlag, E. W.; Rabinovitch, B. S. J. Am. Chem. Soc. 1960, 82 5996

[17] Benson, S. W.; Bose, A. N.; Nangia, P. J. Am. Chem. Soc. 1963 85, 1388.

[18] Dolbier, W. R.; Al-Sader, B. H.; Sellers, S. F.; Koroniak, H. J. Am. Chem. Soc. 1981, 103, 2138.

[19] Roth, W. R.; Kirmse, W.; Hoffmann, W.; Lennartz, H.-W. Chem Ber. 1982, 115, 2508.

[20] Mitsch, R. A.; Neuvar, E. W. J. Phys. Chem. 1966, 70, 546.

[21] Smart, B. E.; Krusic, P. J.; Roe, D. C.; Yang, Z.-Y. J. Fluorine Chem. 2002, 117, 199

[22] O'Neal, H. E.; Benson, S. W. J. Phys. Chem. 1968, 72, 1866.

[23] Zeiger, D. N.; Liebman, J. F. J. Mol. Struc. 2000, 556, 83.

[24] Dolbier, W. R. Acc. Chem. Res. 1981, 14, 195.

[25] Tian, F.; Bartberger, M. D.; Dolbier, W. R. J. Org. Chem. 1998 64,540 .

[26] Eusterwiemann, S.; Martinez, H.; Dolbier, W. R. J. Org. Chem. 2012, 77, 5461

[27] Percy, J. M. Top. Curr. Chem. 1997, 193, 131

[28] Erbes, P.; Boland, W. Helv. Chim. Acta 1992, 75, 766

[29] Brahms, D. L. S.; Dailey, W. P. Chem. Rev. 1996, 96, 1585

[30] Dolbier, W. R.; Battiste, M. A. Chem. Rev. 2003, 103, 1071.

[31] Fedoryński, M. Chem. Rev. 2003, 103, 1099.

[32] Csuk, R.; Eversmann, L. Tetrahedron 1998, 54, 6445.

[33] Itoh, T.; Mitsukura, K.; Furutani, M. Chem. Lett. 1998, 27, 903.

[34] Shibuya, A.; Sato, A.; Taguchi, T. Bioorg. Med. Chem. Lett. 1998, 8, 1979

[35] Seyferth, D.; P. Hopper, S. J. Organomet. Chem. 1971, 26, C62.

[36] Seyferth, D.; Hopper, S. P. J. Org. Chem. 1972, 37, 4070.

[37] Wang, F.; Zhang, W.; Zhu, J.; Li, H.; Huang, K.-W.; Hu, J. Chem. Commun. 2011, 47, 2411.

[38] Yudin, A. K.; Prakash, G. K. S.; Deffieux, D.; Bradley, M.; Bau R.; Olah, G. A. J. Am. Chem. Soc. 1997, 119, 1572.

[39] Li, L.; Wang, F.; Ni, C.; Hu, J. Angew. Chem. Int. Ed. 2013, 52 12390.

[40] Tian, F.; Kruger, V.; Bautista, O.; Duan, J.-X.; Li, A.-R.; Dolbier Jr, W. R.; Chen, Q.-Y. Org. Lett. 2000, 2, 563.

[41] Vatèle, J.-M. Tetrahedron Lett. 2006, 47, 715

[42] Adam, W.; van Barneveld, C.; Golsch, D. Tetrahedron 1996, 52, 2377.

[43] http://openflask.blogspot.co.uk/2014/01/tfdo-synthesisprocedure.html, Accessed February 2014

[44] Gritsch, P. J.; Stempel, E.; Gaich, T. Org. Lett. 2013, 15, 5472.

[45] Bowry, V. W.; Lusztyk, J.; Ingold, K. U. J. Am. Chem. Soc. 1991, 113, 5687.

[46] Newcomb, M.; Johnson, C. C.; Manek, M. B.; Varick, T. R. J. Am. Chem. Soc. 1992, 114, 10915

[47] Newcomb, M. Tetrahedron 1993, 49, 1151

[48] Buttle, L. A.; Motherwell, W. B. Tetrahedron Lett. 1994, 35, 3995.

[49] Barth, F.; O-Yang, C. Tetrahedron Lett. 1991, 32, 5873.

[50] Morikawa, T.; Kodama, Y.; Uchida, J.; Takano, M.; Washio, Y.; Taguchi, T. Tetrahedron 1992, 48, 8915.

[51] Mase, T.; Houpis, I. N.; Akao, A.; Dorziotis, I.; Emerson, K.; Hoang, T.; lida, T.; Itoh, T.; Kamei, K.; Kato, S.; Kato, Y.; Kawasaki, M.; Lang, F.; Lee, J.; Lynch, J.; Maligres, P.; Molina, A.; Nemoto, T.; Okada, S.; Reamer, R.; Song, J. Z.; Tschaen, D.; Wada, T.; Zewge, D.; Volante, R. P.; Reider, P. J.; Tomimoto, K J. Org. Chem. 2001, 66, 6775.

[52] Harrington, P. E.; Tius, M. A. J. Org. Chem. 1999, 64, 4025.

[53] Bremer, M.; Kirsch, P.; Klasen-Memmer, M.; Tarumi, K. Angew. Chem. Int. Ed. 2013, 52, 8880.

[54] Yang, Y.-Y.; Meng, W.-D.; Qing, F.-L. Org. Lett. 2004, 6, 4257.

[55] Munemori, D.; Narita, K.; Nokami, T.; Itoh, T. Org. Lett., 2014 16 , in press, dx.doi.org/10.1021/ol500803r

[56] Miles, J. A. L.; Mitchell, L.; Percy, J. M.; Singh, K.; Uneyama, E. J. Org. Chem. 2007, 72, 12.

[57] Kyne, S. H.; Miles, J. A. L.; Percy, J. M.; Singh, K. J. Org. Chem. 2012, 77, 991

[58] Anderl, T.; Audouard, C.; Miah, A.; Percy, J. M.; Rinaudo, G.; Singh, K. Org. Biomol. Chem. 2009, 7, 5200.
[59] Audouard, C.; Barsukov, I.; Fawcett, J.; Griffith, G. A.; Percy, J. M.; Pintat, S.; Smith, C. A. Chem. Commun. 2004, 1526.

[60] Baldwin, J. E.; Villarica, K. A.; Freedberg, D. I.; Anet, F. A. L. J. Am. Chem. Soc. 1994, 116, 10845.

[61] Baldwin, J. E.; Bonacorsi, S. J. J. Am. Chem. Soc. 1996, 118, 8258.

[62] Mulzer, J.; Huisgen, R.; Arion, V.; Sustmann, R. Helv. Chim Acta 2011, 94, 1359.

[63] Davidson, E. R.; Gajewski, J. J. J. Am. Chem. Soc. 1997, 119, 10543.

[64] Houk, K. N.; Nendel, M.; Wiest, O.; Storer, J. W. J. Am. Chem. Soc. 1997, 119, 10545.

[65] Nendel, M.; Sperling, D.; Wiest, O.; Houk, K. N. J. Org. Chem. 2000, 65, 3259

[66] Doubleday, C.; Li, G. S.; Hase, W. L. Phys. Chem. Chem. Phys 2002, 4, 304

[67] Becke, A. D. J. Chem. Phys. 1993, 98, 5648

[68] Lee, C. T.; Yang, W. T.; Parr, R. G. Phys. Rev. B 1988, 37, 785.

[69] Zhao, Y.; Schultz, N. E.; Truhlar, D. G. J. Chem. Phys. 2005 123, 161103, DOI: 10.1063/1.2126975.

[70] Zhao, Y.; Schultz, N. E.; Truhlar, D. G. J. Chem. Theor. Comput. 2006, 2, 364

[71] Zhao, Y.; Truhlar, D. G. Accounts Chem. Res. 2008, 41, 157

[72] Zhao, Y.; Truhlar, D. G. Theor. Chem. Accounts 2008, 120, 215

[73] Antony, J.; Grimme, S. Phys. Chem. Chem. Phys. 2006, 8, 5287

[74] Grimme, S. J. Comput. Chem. 2006, 27, 1787.

[75] Frisch, M. J.; Gaussian 09, Revision A.1 ed.; Gaussian Inc: Walligford CT, 2009. See the supporting information for the full reference.

[76] Spartan'08, Wavefunction Inc., Irvine, CA, 2008.

[77] Spartan'10, Wavefunction Inc., Irvine, CA, 2010.

[78] Maskill, H. The Physical Basis of Organic Chemistry, OUP Oxford, 1985, Chapter 6, 242

[79] Loncharich, R. J.; Schwartz, T. R.; Houk, K. N. J. Am. Chem Soc. 1987, 109, 14

[80] Bakalova, S. M.; Santos, A. G. J. Org. Chem. 2004, 69, 8475

[81] Kobayashi, Y.; Taguchi, T.; Morikawa, T.; Takase, T.; Takanashi, H. J. Org. Chem. 1982, 47, 3232.

[82] Kobayashi, Y.; Taguchi, T.; Morikawa, T. J. Fluorine Chem. 1982 21,60 . 


\section{Entry for the Table of Contents}

\section{FULL PAPER}

Run rings around fluorine: $A$ difluorinated cyclopentene was accessed in high yields $(70 \%$ over 4 steps) from commercial starting materials using thermal vinyl cyclopropane rearrangement (VCPR). Alongside a relatively mild reaction temperature $\left(100^{\circ} \mathrm{C}\right)$, in situ cyclopropane stereomutation, a competing [3,3]-rearrangement pathway and a sharp and unexpected dependence on alkene configuration were all detected. Kinetic and electronic structure calculations were used to evaluate and rationalise these observations.
David Orr, Prof. Dr. Jonathan M. Percy, * Dr. Tell Tuttle, Dr. Alan R. Kennedy, and Dr. Zoë A. Harrison

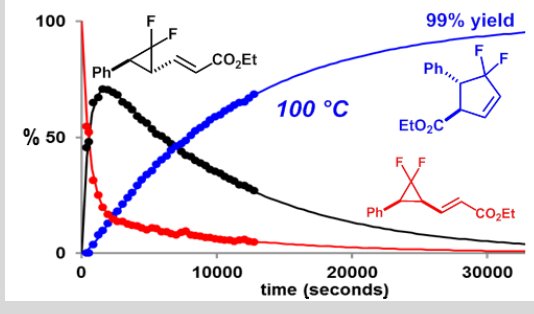

Page No. - Page No.

Evaluating the Thermal

Vinylcyclopropane Rearrangement (VCPR) as a Practical Method for the Synthesis of Difluorinated

Cyclopentenes: Experimental and Computational Studies of Rearrangement Stereospecificity 